\title{
Osteoprotegerin is elevated in pulmonary fibrosis and associates with IPF
}

\section{progression.}

H. Habibie ${ }^{1,2,3}$, Kurnia S.S. Putri ${ }^{4,5}$, Carian E. Boorsma ${ }^{2}$, David M. Brass ${ }^{6}$, Peter Heukels ${ }^{7}$, Marlies Wijsenbeek ${ }^{7}$, Mirjam Kool ${ }^{7}$, Maarten van den Berge ${ }^{2,8}$, Theo Borghuis ${ }^{9}$, CorryAnke Brandsma ${ }^{2,9}$, C Tji Gan ${ }^{8}$ Peter Olinga ${ }^{4}$, Wim Timens ${ }^{2,9}$, Nicolas Kahn ${ }^{10}$, Michael Kreuter $^{10}$, Janette K. Burgess ${ }^{2,9}$, Barbro N. Melgert ${ }^{1,2}$

${ }^{1}$ University of Groningen, Department of Molecular Pharmacology, Groningen Research Institute for Pharmacy, Groningen, The Netherlands. ${ }^{2}$ University of Groningen, University Medical Centre Groningen, GRIAC Research Institute, Groningen, The Netherlands. ${ }^{3}$ Hasanuddin University, Faculty of Pharmacy, Makassar, Indonesia. ${ }^{4}$ University of Groningen, Department of Pharmaceutical Technology and Biopharmacy, Groningen Research Institute for Pharmacy, Groningen, The Netherlands. ${ }^{5}$ Universitas Indonesia, Faculty of Pharmacy, Depok, Indonesia. ${ }^{6}$ Department of Medicine, Pulmonary Division, Duke University Medical Centre, Durham, NC, USA. ${ }^{7}$ Erasmus MC, Department of Pulmonary Medicine, Rotterdam, The Netherlands. ${ }^{8}$ University of Groningen, University Medical Centre Groningen, Department of Pulmonary Diseases, Groningen, The Netherlands. ${ }^{9}$ University of Groningen, University Medical Centre Groningen, Department of Pathology and Medical Biology, Groningen, The Netherlands. ${ }^{10}$ Centre for Interstitial and Rare Lung Diseases, Pneumology, Thoraxklinik, University of Heidelberg and German Centre for Lung Research, Heidelberg, Germany

Correspondence should be addressed to:

Prof. Dr. Barbro N. Melgert.

Department of Molecular Pharmacology,

Antonius Deusinglaan 1, 9713 AV Groningen, The Netherlands.

Email: b.n.melgert@rug.nl

Tel: $+31-50-3632947$

Take home message

Osteoprotegerin is present in fibrotic lung tissue and high serum levels correlate with low lung function and IPF disease progression in this small study, indicating osteoprotegerin may have value as a biomarker to predict IPF progression

Word count for main text : 2978 words

Number of tables and figures : 7

Supplemental data : 1 


\section{ABSTRACT}

Osteoprotegerin (OPG), a decoy receptor for receptor activator of NF-kB ligand (RANKL), is used as a biomarker for assessing severity of liver fibrosis. However, its expression and role in pulmonary fibrosis are unknown. We hypothesized that OPG also has a role in pulmonary fibrosis.

Human and mouse control and fibrotic lung tissue were used to examine OPG expression, and mouse precision-cut lung slices to study OPG regulation in pulmonary fibrosis. Serum from idiopathic pulmonary fibrosis (IPF) patients and controls was analysed to investigate whether OPG levels correlate with disease status as measured by lung function.

OPG-protein levels were significantly higher in mouse and human fibrotic lung tissue compared to control. OPG-mRNA and protein production were induced in mouse precision-cut-lung slices upon TGF $\beta$ stimulation and could be inhibited with galunisertib, a TGF $\beta$ receptor kinase inhibitor. OPG-protein levels in fibrotic mouse lung tissue correlated with degree of fibrosis. Isolated lung fibroblasts from IPF patients had higher OPG-protein levels than control fibroblasts. Serum OPG levels in IPF patients, at first presentation, negatively correlated with diffusing capacity to carbon monoxide. Finally, serum OPG levels higher than $1234 \mathrm{pg} / \mathrm{ml}$ at first presentation were associated with progression of disease in IPF patients.

In conclusion, OPG is produced in lung tissue, associates with fibrosis, and may be a potential prognostic biomarker for IPF disease progression. Validation in a larger cohort is warranted to further explore the role of OPG in pulmonary fibrosis and its potential for assessing the prognosis of fibrotic lung disease in individual patients.

Keywords: silica, biomarker, DLCO, RANKL, lung, collagen 


\section{INTRODUCTION}

2 Pulmonary fibrosis is characterized by extracellular matrix (ECM) deposition and progressive

3 destruction of lung architecture that leads to impaired lung function with high mortality rates [1-

4 3]. Idiopathic pulmonary fibrosis (IPF) is the most severe form of pulmonary fibrosis and has

5 the highest mortality $[4,5]$. One of the challenges in identifying and managing IPF is the lack

6 of biomarkers to assist diagnosing the disease and predicting progression and therefore most

7 patients experience a delayed diagnosis [6]. Having reliable biomarkers to diagnose IPF faster

8 and to track disease progression could improve management of this disease and identification

9 of optimal timing for referral for lung transplantation [7].

Osteoprotegerin (OPG), a decoy receptor for receptor activator of nuclear factor $\mathrm{kB}$

11 ligand (RANKL) and tumour necrosis factor-related apoptosis-inducing ligand (TRAIL) [8], is prominently expressed in bone tissue and best known for its role in the regulation of bone matrix $[9,10]$. We recently showed high OPG expression in liver fibrosis with profibrotic actions of this molecule and the possible use of OPG in assessing treatment responses to antifibrotic drugs [11]. Others have shown associations with fibrotic processes in heart [12] and vasculature [13] and clinically OPG is used in a panel of markers to assess liver fibrosis severity [14]. High OPG expression was also observed in mouse models of silica [15] and bleomycin-induced pulmonary fibrosis [16]. OPG levels increase soon after bleomycin

19 treatment and wane over time, accompanied by a decrease in deposited collagen. We

20 therefore reasoned that OPG expression may be a marker of active fibrotic processes in 21 human pulmonary fibrosis and may also be used as a marker to diagnose pulmonary fibrosis 22 and/or track or predict progression. We investigated this hypothesis using mouse and human 23 lung tissue and serum of patients with IPF and control individuals. 


\section{MATERIALS AND METHODS}

\section{Human tissue}

Human fibrotic lung tissue was collected with informed consent from patients with end-stage IPF at either the University Medical Centre Groningen (UMCG) or at the Erasmus Medical Centre Rotterdam. Nonfibrotic control lung tissue was obtained at the UMCG from patients undergoing surgical resection for carcinoma or chronic obstructive pulmonary disease (COPD, patients characteristics are summarized in table 1).

\section{Isolation and culture of primary fibroblasts}

Primary human lung fibroblasts were isolated from 5 non-fibrotic control patients and 7 patients with IPF (patient characteristics are summarized in table 1). Plated cells were grown to confluence and transferred to low-serum medium. After $24 \mathrm{~h}$, supernatants were collected and stored at $-20{ }^{\circ} \mathrm{C}$ until further analyses.

\section{Serum from patients with IPF and healthy controls}

Sera from 11 patients with IPF were collected in tertiary care centre for ILD, University of Heidelberg, Germany (IRB vote number S-270/2001). Diagnosis of IPF was made in a multidisciplinary team according to current international guidelines [17, 18] Sera from 14 matched healthy individuals were collected at the UMCG, Netherlands (METC numbers $2009 / 007$ and $2016 / 572$, detailed characteristics of the patients and healthy individuals are summarized in table 1). Patients with IPF were followed for a minimum of 1 year after first presentation. Patients were categorized as having progressed if, within a 1-year monitoring period, the percentage predicted diffusing capacity of the lung for carbon monoxide (DLCO) decreased more than $15 \%$ or the percentage predicted force vital capacity (FVC) decreased more than $10 \%$, or in case of death [19]. 
51 Table 1. Characteristics of patients whose lung tissue or sera were used for OPG

52 Collagen $1 \alpha 1$ analyses and fibroblast isolation (medians with range are presented).

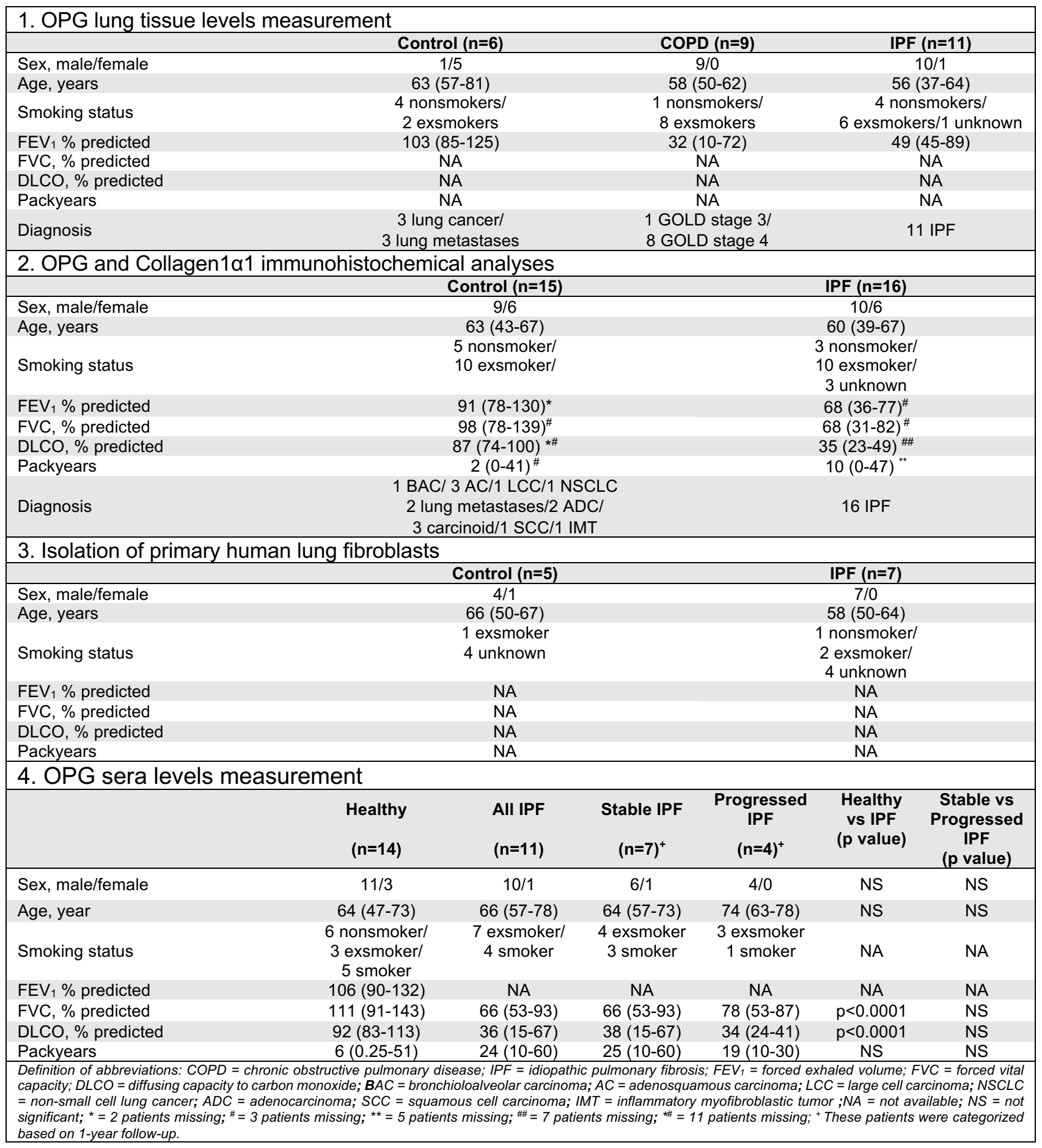




\section{Animal experiments}

All animal experiments were approved by the Institutional Animal Care and Use Committee, The University of Groningen (DEC6064) and (DEC6416AA). Male C57BL/6 mice were obtained from Harlan (Zeist, The Netherlands). Fibrosis was induced using intratracheal installation of Min-U-Sil 5 crystalline silica $(0.2 \mathrm{~g} / \mathrm{kg})$ [15]. Mice were sacrificed after 6 weeks and serum and lung tissues collected.

Lungs of healthy male C57BL/6 mice were used to make precision-cut lung slices. Slices were incubated for $48 \mathrm{~h}$ with or without $5 \mathrm{ng} / \mathrm{ml} \mathrm{TGF} \beta 1$ in the presence or absence of $10 \mu \mathrm{M}$ galunisertib. Slices and supernatants were collected for further analyses.

\section{Protein isolation from lung tissue}

Protein was isolated from frozen human or mouse lung tissue in $0.25 \mathrm{M}$ Tris/ $\mathrm{HCl}$ buffer with 2.5\% Igepal, 0.5\% SDS, Protease Inhibitor Cocktail (Boehringer Mannheim, Germany), pH 7.5. Samples were stored at $-80^{\circ} \mathrm{C}$ for later analyses.

\section{ELISA}

71 Human and mouse OPG levels in lung tissue, serum and culture supernatants were assessed using an ELISA kit according to manufacturer's instructions (R\&D, Minneapolis, USA)

\section{Immunohistochemistry}

75 Immunohistochemical analyses of collagen I, collagen $1 \alpha 1$ (Col1 $\alpha 1)$ and OPG were performed on paraffin sections of mouse or human lung tissue. The amount of collagen I deposition in the mouse lung was quantified using ImageScope software (Aperio, Burlingame, USA) and OPG and Col1a1 in human lung were assessed using ImageJ software (version 1.47, NIH, USA) [20]. 
Quantitative Real-time PCR

81 Total mRNA was isolated from tissues using a Maxwell ${ }^{\circledR}$ LEV simply RNA Cells/Tissue kit (cat\#

82 AS1280, Promega, Madison, WI) according to the manufacturer's instructions. Col1a1, 83 fibronectin, OPG, plasminogen activator inhibitor-1 (PAl1), and 18s mRNA was detected with 84 primers summarized in supplemental table 1. mRNA expression was normalized to $18 \mathrm{~s}$.

85

Statistical analyses

87 Statistical differences between two groups without normal distribution were assessed using 88 Mann-Whitney U for unpaired data or Wilcoxon for paired data. D'agostino-Pearsons test was used to examine normality. Paired or unpaired student's t-test was used for normal data. For the comparison of multiple groups, we used Kruskal Wallis. Correlations were assessed by

91 Spearman or Pearson test. Receiver-operator characteristic (ROC) curves and Kaplan-Meier 92 curves were used to model the utility of serum OPG as a marker of disease progression and 93 to model survival respectively. Significance was considered when $p<0.05$. The data were 94 analysed using GraphPad Prism 8 (GraphPad software, San Diego, USA).

96 More detailed information is available in the online supplemental "Material and Methods" 97 section. 


\section{RESULTS}

OPG protein levels are higher in mice with silica-induced lung fibrosis and in human

\section{1 fibrotic lung tissues}

102 We first examined OPG levels in the lungs of silica-treated mice and observed that OPG levels were significantly higher in fibrotic lungs compared to control lungs (fig. 1a). To confirm the

104 development of fibrosis in our mouse model we examined collagen I protein deposition in lungs

105 of silica-exposed mice and found significantly higher collagen expression and deposition in 106 lungs of mice exposed to silica (supplemental data fig. 1a-b). We also measured OPG levels 107 in serum, but found no significant differences between control and silica-exposed mice 108 (supplemental data fig. 1c). We then measured OPG levels in lung tissue from patients with 109 end stage IPF and found that OPG levels were significantly higher when compared to lung 110 tissue of control patients (Figure 1b).

\section{a) Mouse}

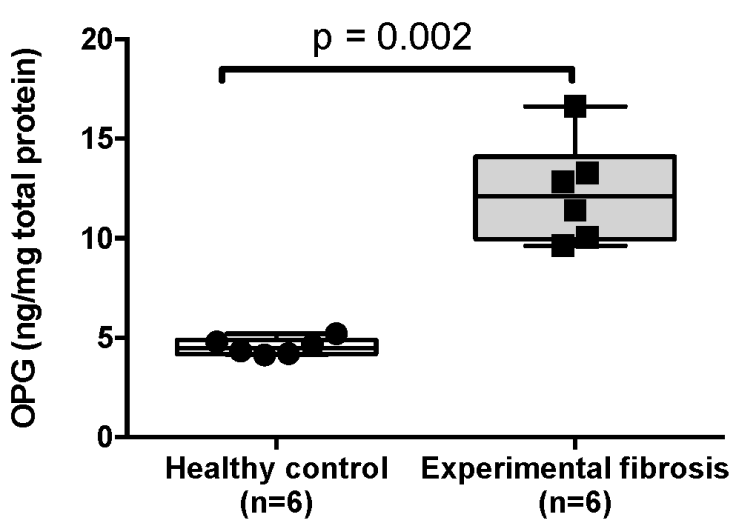

b) Human

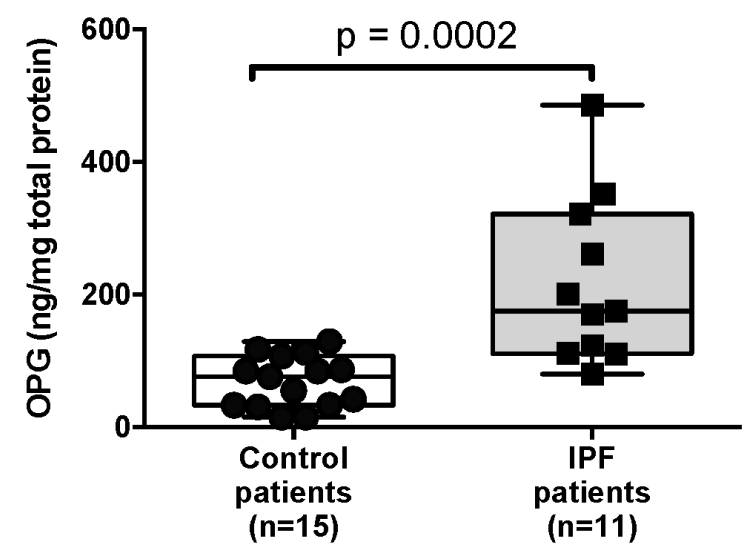

112 Figure 1. OPG protein levels are higher in fibrotic conditions in both mouse and human lung

113 tissue. (a) OPG protein levels were measured in mouse lung tissues collected from mice 6 weeks after

114 receiving silica (experimental fibrosis, $n=6$ ) or saline (healthy control, $n=6$ ). (b) in human lung tissue

115 obtained from 15 patients undergoing surgical resection for carcinoma or COPD (control patients) and

116 from 11 patients with idiopathic pulmonary fibrosis (IPF) undergoing lung transplantation. Differences 
117 between groups were tested with Mann Whitney $U$ test (mouse) or unpaired student $t$ test (human),

$118 p<0.05$ was considered significant.

120 TGF $\beta$ induces expression of OPG and fibrosis-associated markers in mouse precision-

121 cut lung slices.

122 To determine whether OPG can be produced by lung tissue, we added the profibrotic cytokine

123 TGF $\beta 1$ to precision-cut lung slices of healthy mouse lung tissue. To further investigate the

124 association between OPG production and fibrosis development and the potential regulation by

125 antifibrotic treatment, we conducted these experiments with or without galunisertib, a TGF $\beta$ -

126 receptor type I kinase inhibitor. We found significantly higher mRNA expression and protein

127 production of OPG, along with the fibrosis-associated genes PAI1 and fibronectin following

128 TGF $\beta 1$ treatment as compared to untreated controls and this could be blocked by galunisertib

129 (fig. 2a-c). Although mRNA expression of Col1a1 (fig. 2d) was not significantly higher after

130 TGF $\beta 1$ treatment, galunisertib still significantly attenuated TGF $\beta 1$-induced levels of Col1a1 131 mRNA. 
a) OPG mRNA

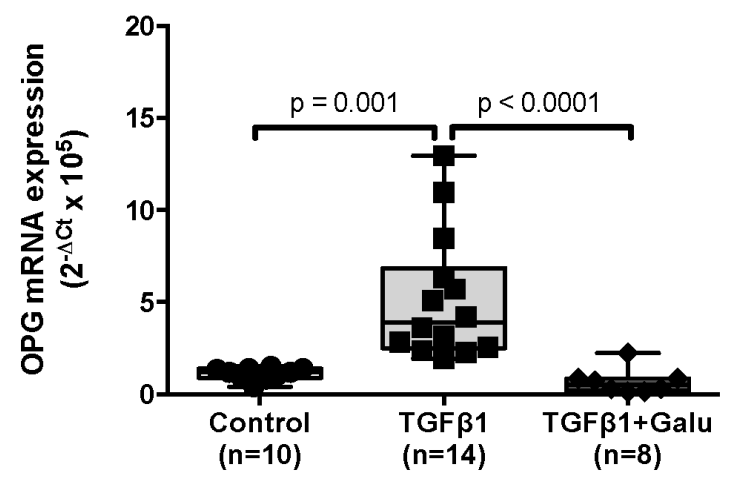

b)

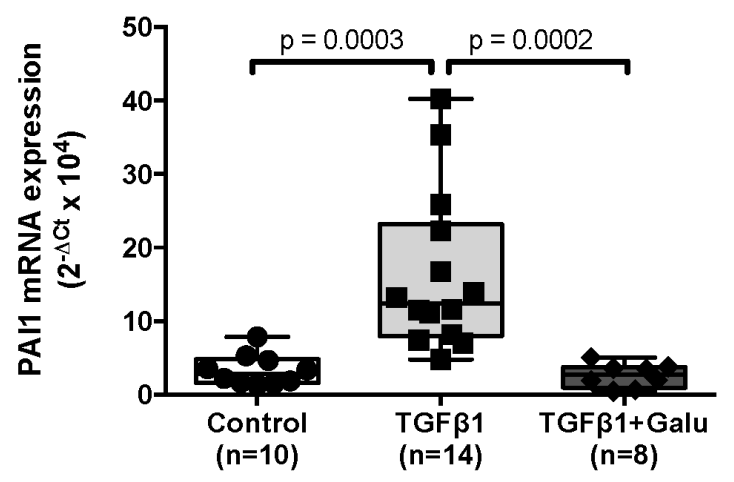

OPG Protein

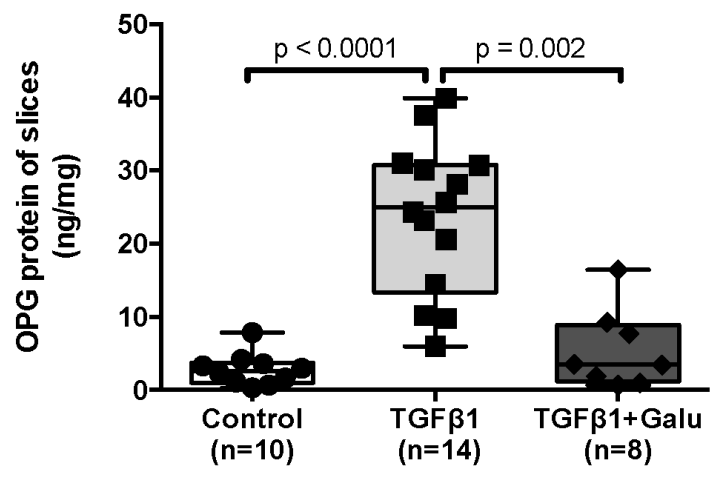

c)

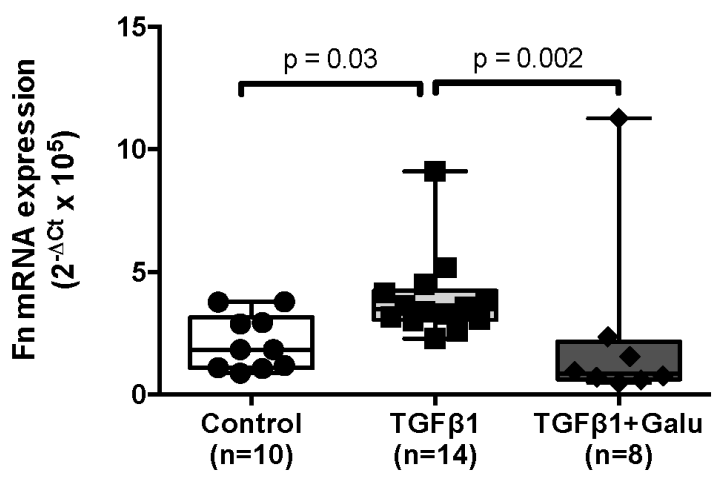

d)

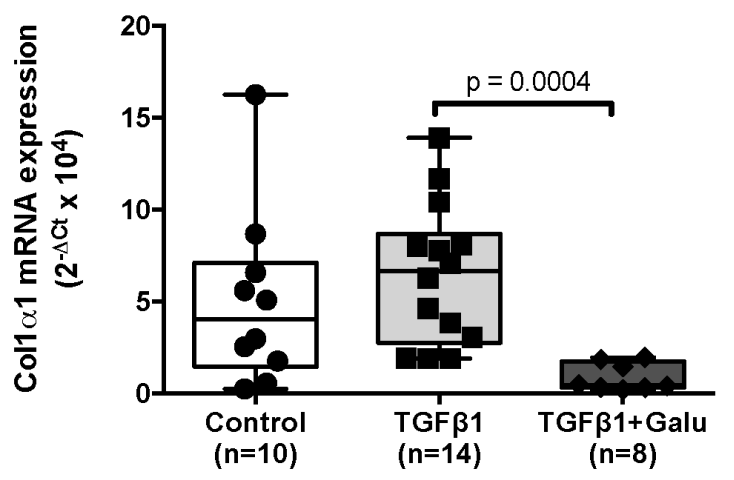

133 Figure 2. TGF $\beta$ induces expression of OPG and fibrosis-associated markers in mouse precision-

134 cut lung slices. Mouse lung slices were treated with $5 \mathrm{ng} / \mathrm{mL}$ TGF $\beta 1$ with or without $10 \mu M$ galunisertib

135 for 48 hours and compared to untreated controls for expression of (a) OPG mRNA and OPG protein,

136 fibrosis-associated markers (b) plasminogen activator inhibitor-1 (PA/1), (c) fibronectin (Fn), and (d)

137 Col1a1 mRNA. Differences between groups were analysed with a Kruskal Wallis test. $p<0.05$ was considered statistically significant. 
OPG expression correlates with fibrosis-associated markers in mouse lung slices.

140 To investigate whether the expression of OPG correlated with fibrosis-associated markers, we 141 compared OPG mRNA expression levels with those of Col1a1, fibronectin, and PAI1 in all 142 treatment groups of slices (fig. 2). We found that OPG mRNA expression significantly 143 correlated with mRNA expression of Col1a1 (fig. 3a), fibronectin (fig. 3b) and PAl1 (fig. 3c).

a)

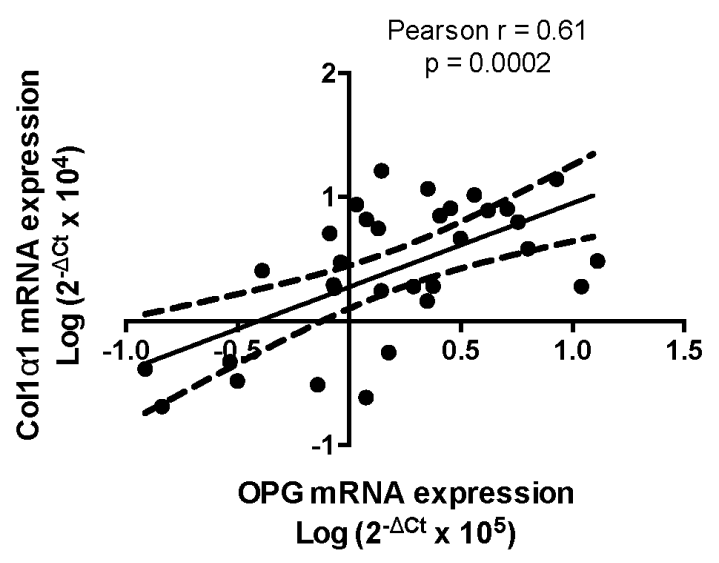

b)

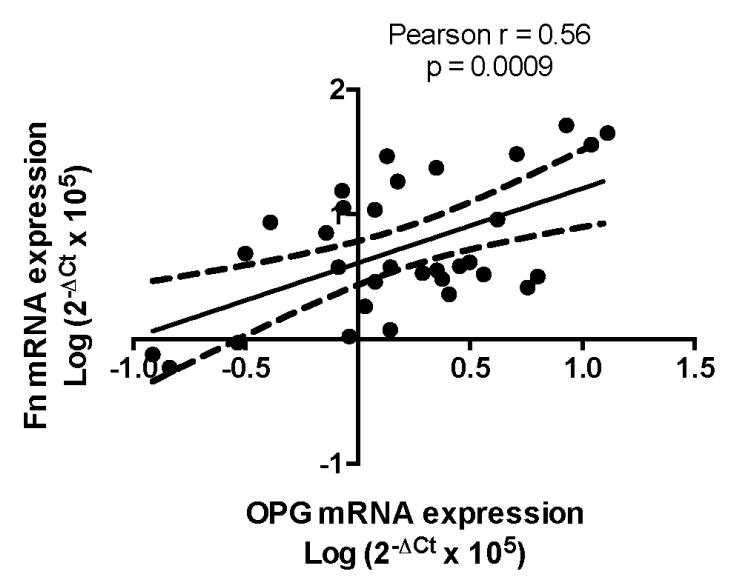

c)

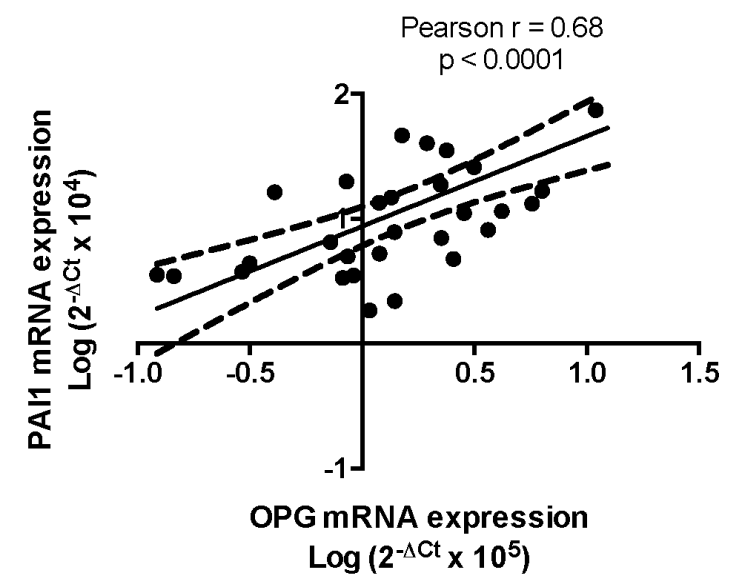

145 Figure 3. OPG mRNA expression levels correlate with expression of fibrosis-associated markers

146 in mouse lung slices. In untreated mouse lung slices and slices treated with TGF $\beta 1$ with or without galunisertib, OPG mRNA expression correlated positively with mRNA expression of fibrosis-associated markers (a) Col1a1, (b) fibronectin (Fn) and (c) PAl1. Correlations were calculated using a Pearson test and $p<0.05$ was considered significant. 
bioRxiv preprint doi: https://doi org/10.1101/2020 12 02 408062; this version posted December 3, 2020. The copyright holder for this

preprint (which was not certified by peer review) is the author/funder. All rights reserved. No reuse allowed without permission.

OPG is abundantly present in fibrotic areas in mouse lung tissue and OPG protein levels

152 positively correlate with the degree of fibrosis.

153 To investigate whether OPG expression could be related to the degree of fibrosis in lung tissue,

154 we assessed OPG (fig. 4) and collagen I deposition (supplemental data fig. 1a-c) in lung tissue

155 of mice exposed to silica. Immunohistochemistry for OPG showed that OPG localized in the

156 smooth muscle layers around vessels and airways in lung tissue of control mice (fig. 4a). In

157 lung tissue of mice exposed to silica, OPG expression was also observed within areas of

158 fibrosis (fig. 4b). Furthermore, we found that OPG protein expression significantly correlated

159 with collagen I deposition in lung tissue of mice (Fig. 4d). OPG presence in mouse lung tissue

160 did not correlate with OPG levels in serum (supplemental data fig. 2a). and neither did serum

161 OPG levels correlate with collagen I content in lung tissue (supplemental data fig. 2b)

a)

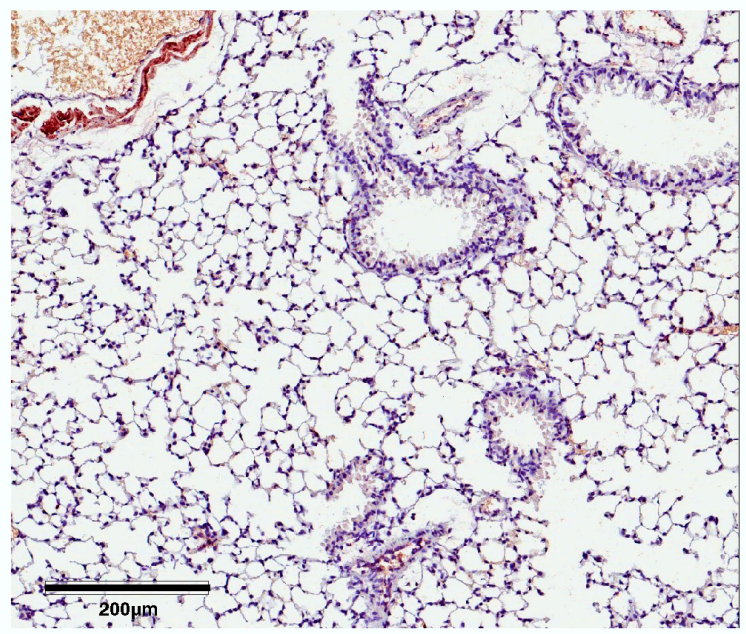

c)

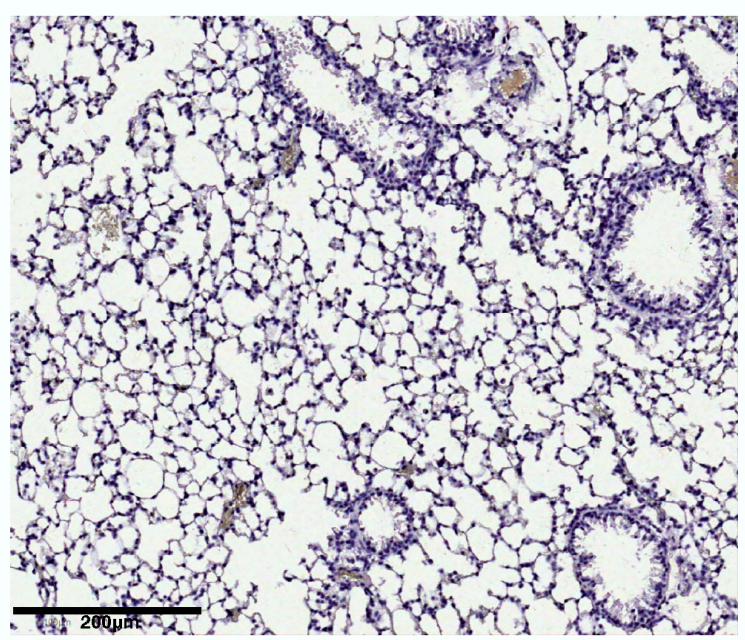

b)

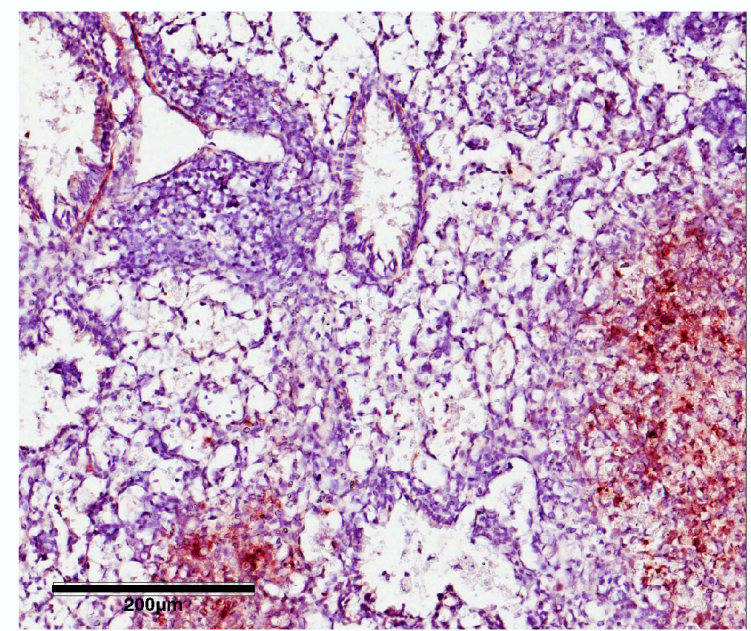

d)

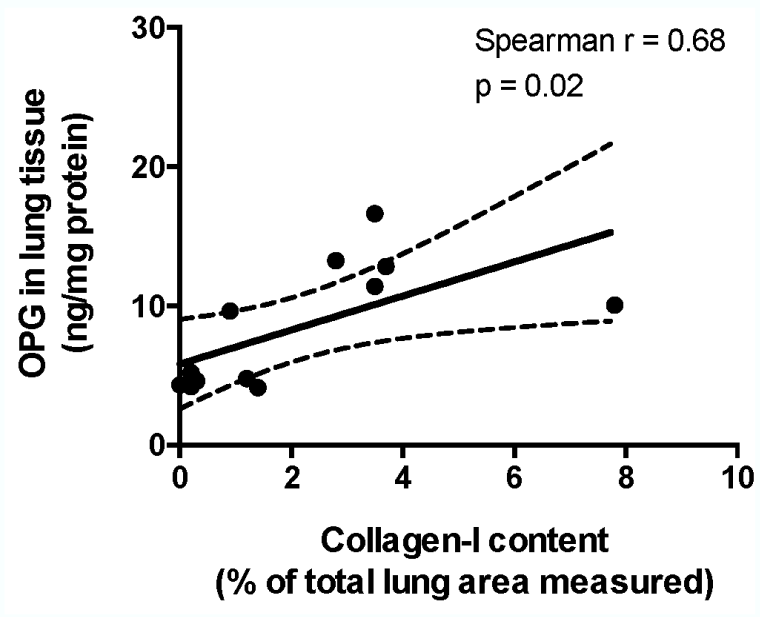



positively correlate with the degree of fibrosis in mice. Mice were exposed to silica or saline and sacrificed after 6 weeks. Representative sections of lung tissue stained for OPG (OPG: red, nuclei: blue) from (a) saline-exposed control and (b) silica-exposed mice. (c) Negative control for the OPG staining. (d) In lung tissue of saline-exposed control mice $(n=6)$ and silica-exposed mice ( $n=6)$, OPG levels positively correlated with collagen I levels in lung tissue. Correlation was calculated using a Spearman test and $p<0.05$ was considered significant.

\section{fibroblasts.}

173 We then investigated OPG and collagen 1a1 deposition in lung tissue of patients with or 174 without IPF. Similar to what we observed in mouse lung tissue, OPG localized to the smooth 175 muscle layers around vessels and airways in lung tissue of control patients and was also found 176 in epithelial cells, macrophages, and endothelial cells. In lung tissue of patients with IPF, OPG expression was additionally observed within areas of fibrosis development/fibroblast foci (fig. 5a). Furthermore, we quantified expression of OPG and found significantly more OPG-positive

179 pixels and more intense OPG staining (Fig. 5b) in lung tissue of patients with IPF than in that 180 of control patients. The same was found for collagen $1 \alpha 1$ deposition: significantly more 181 collagen 1a1-positive pixels and more intense collagen $1 \alpha 1$ staining (Fig. $5 \mathrm{c}$ ) in lung tissue of 182 patients with IPF than in lung tissue of control patients. Despite these similarities in staining, 183 we did not find a significant correlation between OPG and collagen $1 \alpha 1$ deposition in human 184 IPF lung tissue as we had seen in mice (data not shown). For both types of staining we found 185 a lower percentage of positively stained area in IPF lung tissue compared to control, due to 186 the increase in tissue mass in fibrotic lungs compared to control lung tissues (Supplemental 187 data fig. 3a-b).

As more OPG staining was observed in fibrotic area/fibroblast foci, we investigated if 189 (myo)fibroblasts could be a source of OPG. To this end, we isolated primary human fibroblasts from patients with IPF and from control patients. We observed that human lung fibroblasts 
191 produced copious amounts of OPG and that lung fibroblasts from patients with IPF produced

192 significantly more OPG than lung fibroblasts isolated from control patients (fig. 5d).

a)

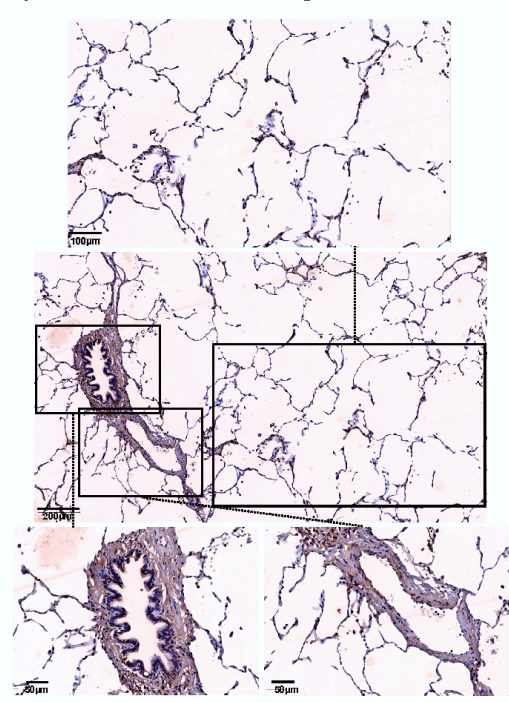

IPF lung

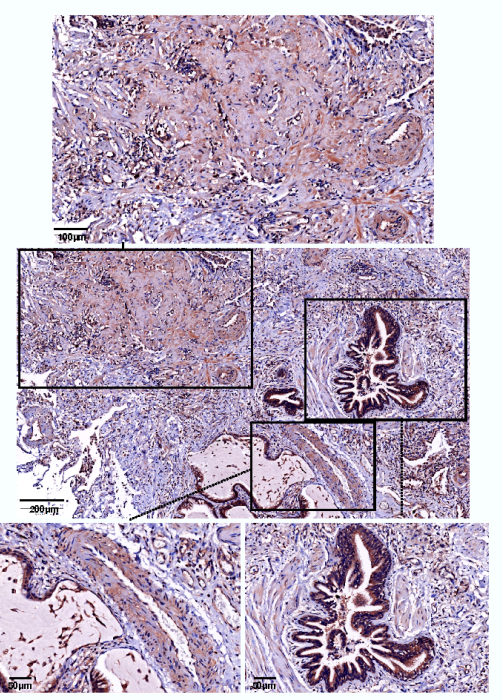

OPG negative staining

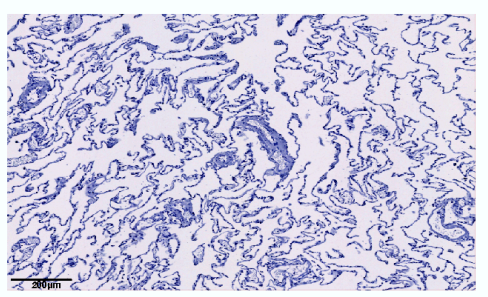

b) Osteoprotegerin
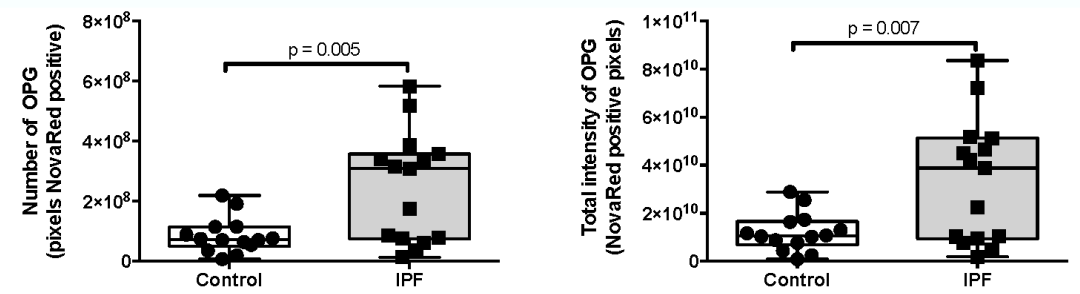

c) Collagen 1a1
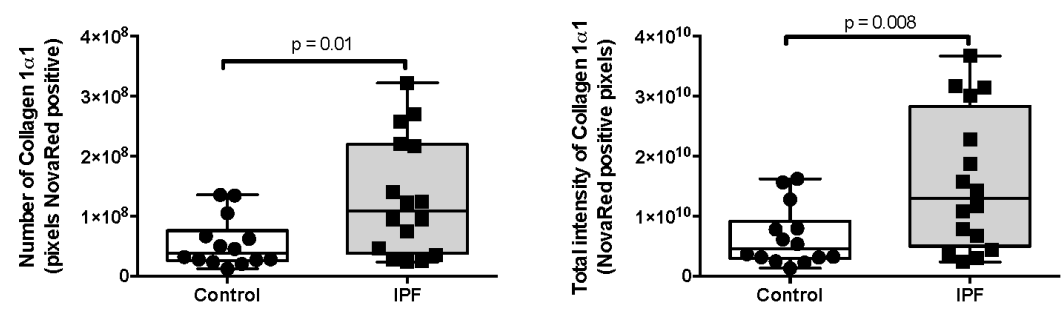

d)

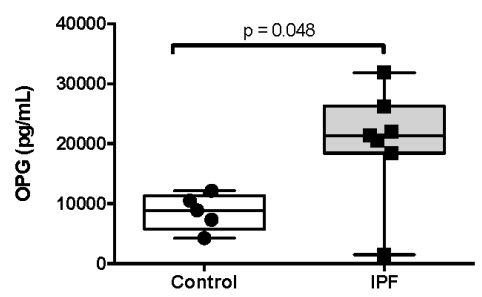

Figure 5. OPG is abundantly present in human IPF lung tissue and produced by lung fibroblasts.

195 (a). Representative sections of lung tissue stained for OPG (OPG; red, nuclei; blue) from a control patient, a patient with IPF and negative control for the OPG staining. (b) Numbers of OPG-positive pixels 
and total intensity of OPG-positive pixels, (c) numbers of collagen 1a1-positive pixels and total intensity of collagen 1a1-positive pixels were quantified using imageJ. (d) Human primary fibroblasts isolated

199 from lung tissue of nonfibrotic control patients and patients with IPF were cultured for 24 hours and levels of secreted OPG protein were quantified. Differences between groups were tested with unpaired student $t$ test $(b-c)$ or Mann Whitney $U$ test (d). $p<0.05$ was considered significant.

205 To determine whether OPG could serve as a blood-based biomarker for IPF, we measured 206 OPG levels in serum from patients with IPF, collected at first presentation and compared them 207 to serum of age and gender matched healthy individuals. Serum OPG levels of patients with 208 IPF were not significantly different as compared to healthy individuals (fig. 6a). However, 209 patients with IPF had more variable OPG levels than healthy controls, similar to the pattern 210 that was seen for OPG levels in lung tissue (fig. 1a). To investigate whether OPG levels reflect 211 disease status, we examined correlations between serum OPG levels and lung function 212 parameters in patients with IPF at first presentation and found an inverse correlation of 213 elevated OPG levels to decreased DLCO levels (Pearson $r=-0.64, p=0.035$ ) (fig. 6b). A 1-year 214 follow-up showed that OPG levels did not change significantly over time (Supplemental data 215 fig. 4), however, there was significant disease progression in 4 patients while 7 patients 216 remained stable (table 1). For OPG, the area under the curve of the ROC analysis was 0.85 $217(95 \% \mathrm{Cl}, 0.62-1.09 ; \mathrm{P}=0.058)$ (fig. 6c). Thresholds for OPG were generated from this curve and 218 sensitivity and specificity at every OPG level calculated. At a threshold of $1234 \mathrm{pg} / \mathrm{mL}$, serum 219 OPG level identified patients with IPF with significant disease progression with the highest 220 value for both sensitivity and specificity ( $100 \%$ and $71.43 \%$ respectively) (supplemental table 221 2). Finally, Kaplan-Meier analysis showed that serum OPG levels greater than $1234 \mathrm{pg} / \mathrm{mL}$ 222 were associated with a shorter survival time than levels below $1234 \mathrm{pg} / \mathrm{mL}(p=0.03$, fig. $6 \mathrm{~d})$ in 223 this small group of patients. 
a)

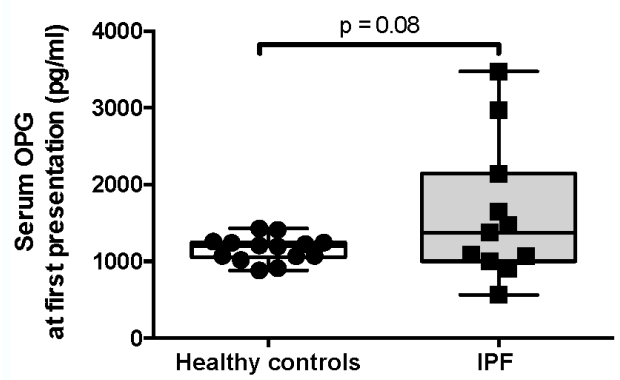

c)

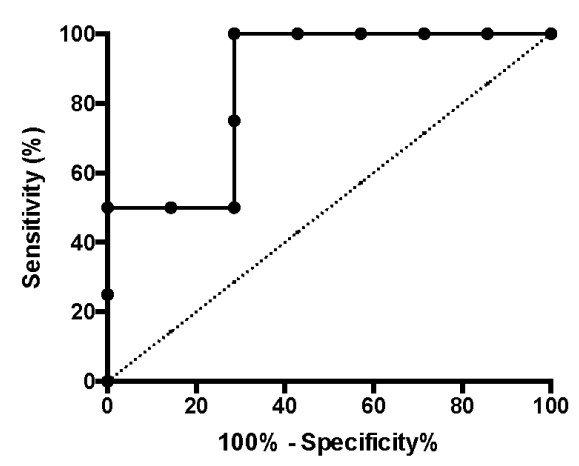

b)

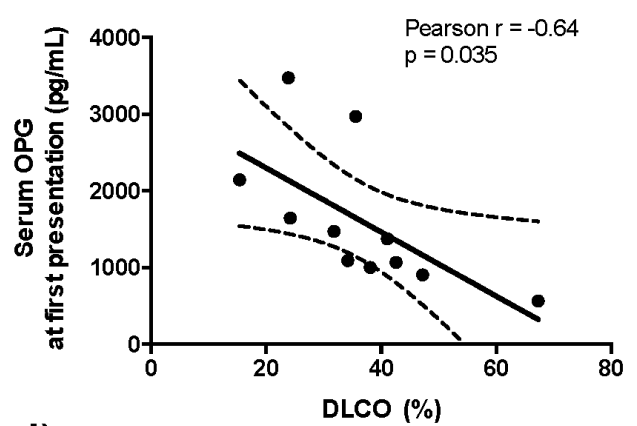

d)

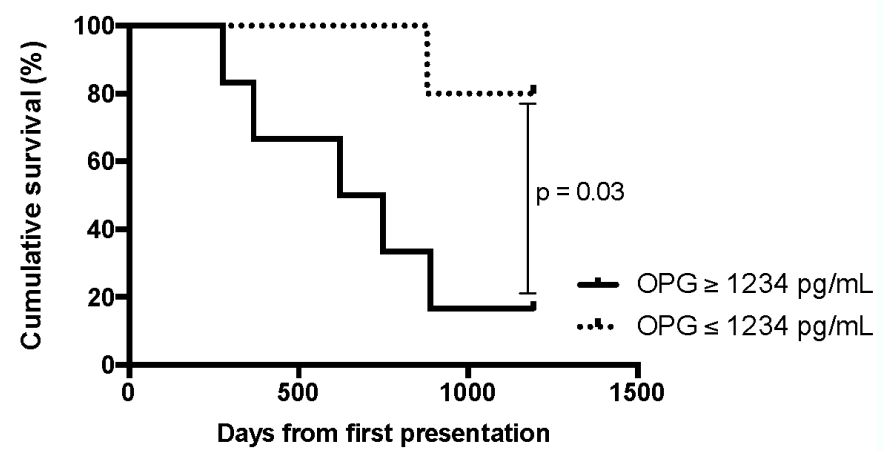

Figure 6. OPG levels negatively correlate with DLCO and associate with progression of disease

in patients with IPF. (a) Patients with IPF were monitored for at least 1 year after the initial visit. Serum presentation in the hospital correlated negatively to the diffusion capacity for carbon monoxide (DLCO)

C) curve was generated based on OPG levels in patients who progressed $(n=4)$ compared to the levels of non-progressed patients $(n=7$, area under curve, $0.85 ; 95 \% \mathrm{Cl}, 0.62-1.09 ; p=0.058)$. (d) Survival time of patients with serum OPG levels greater than $1234 \mathrm{pg} / \mathrm{mL}(n=6)$ were compared to patients with levels below $1234 \mathrm{pg} / \mathrm{mL}(n=5)$ using

234 Kaplan-Meier analysis. Differences between groups were tested with an unpaired t test. Correlations were calculated using a Pearson test. $p<0.05$ was considered significant.

\section{DISCUSSION}

239 Our study has shown that OPG is expressed in the lung and is higher in fibrotic lung tissue.

240 Interestingly, although OPG serum levels did not distinguish patients with IPF from healthy 241 controls, elevated OPG levels at first hospital presentation were associated with disease 
242 progression. In our small cohort, patients with serum OPG levels greater than $1234 \mathrm{pg} / \mathrm{mL}$ 243 progressed more rapidly than patients with lower levels. This is an important initial finding since

244 information on the likelihood of disease progression is essential as it can guide clinicians to 245 tailor clinical management of these patients. However, further validation in a larger cohort is warranted to explore the potential of OPG for assessing the prognosis of fibrotic lung disease.

247 This finding also suggests OPG has a pathological role in IPF and that it may be important 248 during phases or in regions of active fibrosis in the lung. Individual OPG levels in both 249 progressed and stable patients did not change significantly over time. This may suggest that 250 the maximal OPG production associated with an active disease process had already been 251 attained before the patients presented at the clinic. Our studies with murine precision-cut lung slices confirm this rapid and early response of OPG to a fibrotic trigger. Some publications have suggested that OPG levels increase in fibrotic conditions to counteract higher RANKL levels, possibly originating from bone in response to the actions of 255 IL-6 and TNF- $\alpha[21,22]$. However, we found RANKL levels were similar to controls in patients 256 with IPF and mice with pulmonary fibrosis (data not shown). TGF $\beta$, the hallmark cytokine of 257 fibrosis, induced OPG production in mouse precision-cut lung slices which could be inhibited 258 by galunisertib. Together these data suggest that OPG in fibrotic conditions is not produced in response to RANKL but in response to TGF $\beta$ and/or possibly other profibrotic mediators. In

260 mice, OPG levels in fibrotic lung tissue positively correlated with degree of fibrosis in lung 261 tissue, but serum OPG levels did not correlate with the degree of fibrosis (or with lung tissue 262 OPG levels). Interestingly, a recent study by Tsukasaki et al. suggested that locally produced 263 OPG was crucial for its local functions and that its role was limited to the tissue in which it was 264 produced [23, 24]. Moreover, we also found that lung fibroblasts isolated from IPF lung tissue 265 produced more OPG than those from non-diseased controls. Therefore, our findings strongly 266 support the concept that OPG is produced locally in lung tissue and is associated with the local 267 fibrotic process.

268 The biological role of OPG is still under investigation. As the decoy receptor for RANKL 269 and TRAIL, OPG could exert its effects through either of these ligands. No biological role for 
RANKL in lung tissue has been described, but TRAIL was shown to have anti-inflammatory

271 effects by accelerating neutrophil apoptosis and antifibrotic effects by inducing apoptosis in

272 (myo)fibroblasts [25-28]. Indeed, TRAIL was present at lower levels in patients with IPF and 273 mice with bleomycin-induced pulmonary fibrosis [29]. By neutralizing TRAIL, OPG could dampen these beneficial effects, thereby contributing to progression of fibrosis. OPG between controls and patients with IPF [29] or between mice with and without fibrosis, making the use of OPG alone as a serum marker for diagnosis of IPF unlikely. We did find higher OPG levels in lung tissue of both patients with IPF and mice with fibrosis (which McGrath et al. did not investigate), suggesting that maybe a more lung-localized form of sampling (BAL/sputum) has merits, but this needs further investigation. We did notice more variation in OPG levels in patients with IPF than in controls (in both serum and lung tissue) and therefore investigated correlations with lung function. Unlike the previous study, we found 283 a negative correlation between OPG levels in serum and DLCO at first presentation in patients 284 with IPF [29]. The difference between these findings may be caused by the sampling time; we analysed serum levels of patients at the time of first presentation to our tertiary referral hospital, while McGrath used samples from patients throughout their disease progression. Interestingly, in patients with stage II sarcoidosis a negative correlation between OPG levels in BALF and

288 DLCO was recently reported [30]. Patients with stage II sarcoidosis, however, do not have 289 fibrotic involvement (yet), which may point again at OPG possibly being an indicator of early 290 fibrotic activity. An alternative explanation comes from clinical studies showing that higher 291 serum OPG levels are associated with vascular calcification [31]. If these calcifications occur 292 in the pulmonary vascular bed, this may also explain the inverse correlation between OPG and 293 DLCO in pulmonary fibrosis patients.

Several serum biomarkers of IPF severity and progression have been studied and 295 characterized [32]. These include matrix metalloproteinases 1 and 7 [33], surfactant proteins 296 SP-A and SP-D [34], SP-B [35] and fibulin-1 [36]. However, there is not a single biomarker that 297 can accurately diagnose and predict likelihood of progression of IPF. Numerous factors are 
298 known to contribute to fibrosis development and these may vary between patients. Therefore,

299 a panel of biomarkers may be a more useful approach and OPG may contribute important

300 information to this panel. An excellent example is seen in the liver field, in which a panel of 301 serum markers for staging of liver fibrosis severity performed better with the addition of OPG 302 [37].

303 In summary, our study revealed that OPG expression is upregulated in pulmonary 304 fibrosis, is induced by TGF $\beta$, and corresponds to the degree of fibrosis in the lungs of mice. 305 We translated our findings to patients with IPF: serum OPG levels negatively correlated with 306 DLCO and above a threshold of $1234 \mathrm{pg} / \mathrm{ml}$ was associated with disease progression. This 307 suggests possible value of OPG as a prognostic marker for likelihood of disease progression 308 and warrants evaluation in a larger cohort of patients with IPF and other fibrotic lung diseases.

\section{Support statement}

This study was supported by the Pender foundation in the Netherlands, Lungenfibrose eV in Germany, and the Indonesia Endowment Fund for Education (LPDP, 201701220410176) through a PhD scholarship awarded to H. Habibie. 


\section{Author contributions}

Habibie: Study design, collection and assembly of data, data analysis and interpretation, manuscript writing, critical reading and revision.

Kurnia S.S Putri: Collection and assembly of data, data analysis and interpretation, critical reading and revision.

Carian E. Boorsma: Collection and assembly of data, data analysis and interpretation, critical reading and revision.

David M. Brass: Study design, critical reading and revision.

Peter Heukels: Collection and assembly of data, experimental material support, critical reading and revision.

Marlies Wijsenbeek: Collection and assembly of data, experimental material support, critical reading and revision.

Mirjam Kool: Collection and assembly of data, experimental material support, critical reading and revision.

Maarten van den Berge: Collection and assembly of data, experimental material support, critical reading and revision.

Theo Borghuis: Collection and assembly of data, data analysis and interpretation, critical reading and revision.

Corry-Anke Brandsma: Collection and assembly of data, experimental material support, critical reading and revision.

C Tji Gan: Collection and assembly of data, experimental material support, critical reading and revision.

Peter Olinga: Collection and assembly of data, experimental material support, critical reading and revision.

Wim Timens: Collection and assembly of data, experimental material support, critical reading and revision.

Nicolas Kahn: Collection and assembly of data, experimental material support, data analysis and interpretation, critical reading and revision.

Michael Kreuter: Collection and assembly of data, experimental material support, data analysis and interpretation, critical reading and revision.

Janette K. Burgess: Study design, data analysis and interpretation, manuscript writing, critical reading and revision.

Barbro N. Melgert: Collection and assembly of data, study design, data analysis and interpretation, financial support, manuscript writing, critical reading and revision. 


\section{REFERENCES}

1. du Bois RM. Idiopathic pulmonary fibrosis: present understanding and future options. Eur Respir Rev 2011: 20(121): 132-133.

2. Strieter RM. What differentiates normal lung repair and fibrosis? Inflammation, resolution of repair, and fibrosis. Proc Am Thorac Soc 2008: 5(3): 305-310.

3. Wilson MS, Wynn TA. Pulmonary fibrosis: pathogenesis, etiology and regulation. Mucosal Immunol 2009: 2(2): 103-121.

4. Demedts M, Wells AU, Anto JM, Costabel U, Hubbard R, Cullinan P, Slabbynck H, Rizzato G, Poletti V, Verbeken EK, Thomeer MJ, Kokkarinen J, Dalphin JC, Taylor AN. Interstitial lung diseases: an epidemiological overview. Eur Respir J Supp/ 2001: 32: 2s-16s.

5. Raghu G, Weycker D, Edelsberg J, Bradford WZ, Oster G. Incidence and prevalence of idiopathic pulmonary fibrosis. Am J Respir Crit Care Med 2006: 174(7): 810-816.

6. Robbie H, Daccord C, Chua F, Devaraj A. Evaluating disease severity in idiopathic pulmonary fibrosis. Eur Respir Rev 2017: 26(145).

7. Martinez FJ, Chisholm A, Collard HR, Flaherty KR, Myers J, Raghu G, Walsh SL, White ES, Richeldi L. The diagnosis of idiopathic pulmonary fibrosis: current and future approaches. Lancet Respir Med 2017: 5(1): 61-71.

8. Reid P, Holen I. Pathophysiological roles of osteoprotegerin (OPG). Eur J Cell Biol 2009: 88(1): 1-17.

9. Vitovski S, Phillips JS, Sayers J, Croucher PI. Investigating the interaction between osteoprotegerin and receptor activator of NF-kappaB or tumor necrosis factor-related apoptosis-inducing ligand: evidence for a pivotal role for osteoprotegerin in regulating two distinct pathways. J Biol Chem 2007: 282(43): 31601-31609.

10. Harada S, Rodan GA. Control of osteoblast function and regulation of bone mass. Nature 2003: 423(6937): 349-355.

11. Adhyatmika A, Beljaars L, Putri KSS, Habibie H, Boorsma CE, Reker-Smit C, Luangmonkong T, Guney B, Haak A, Mangnus KA, Post E, Poelstra K, Ravnskjaer K, 
Olinga P, Melgert BN. Osteoprotegerin is More than a Possible Serum Marker in Liver Fibrosis: A Study into its Function in Human and Murine Liver. Pharmaceutics 2020: 12(5).

12. Shen A, Hou X, Yang D, Liu T, Zheng D, Deng L, Zhou T. Role of osteoprotegerin and its gene polymorphisms in the occurrence of left ventricular hypertrophy in essential hypertensive patients. Medicine (Baltimore) 2014: 93(29): e154.

13. Toffoli B, Pickering RJ, Tsorotes D, Wang B, Bernardi S, Kantharidis P, Fabris B, Zauli G, Secchiero P, Thomas MC. Osteoprotegerin promotes vascular fibrosis via a TGF-beta1 autocrine loop. Atherosclerosis 2011: 218(1): 61-68.

14. Bosselut N, Taibi L, Guechot J, Zarski JP, Sturm N, Gelineau MC, Poggi B, Thoret S, Lasnier E, Baudin B, Housset C, Vaubourdolle M, Group AHF. Including osteoprotegerin and collagen IV in a score-based blood test for liver fibrosis increases diagnostic accuracy. Clin Chim Acta 2013: 415: 63-68.

15. Brass DM, McGee SP, Dunkel MK, Reilly SM, Tobolewski JM, Sabo-Attwood T, Fattman CL. Gender influences the response to experimental silica-induced lung fibrosis in mice. Am J Physiol Lung Cell Mol Physiol 2010: 299(5): L664-671.

16. Brass DM, Yang IV, Kennedy MP, Whitehead GS, Rutledge H, Burch LH, Schwartz DA. Fibroproliferation in LPS-induced airway remodeling and bleomycin-induced fibrosis share common patterns of gene expression. Immunogenetics 2008: 60(7): 353-369.

17. Raghu G, Remy-Jardin M, Myers JL, Richeldi L, Ryerson CJ, Lederer DJ, Behr J, Cottin V, Danoff SK, Morell F, Flaherty KR, Wells A, Martinez FJ, Azuma A, Bice TJ, Bouros D, Brown KK, Collard HR, Duggal A, Galvin L, Inoue Y, Jenkins RG, Johkoh T, Kazerooni EA, Kitaichi M, Knight SL, Mansour G, Nicholson AG, Pipavath SNJ, Buendia-Roldan I, Selman M, Travis WD, Walsh S, Wilson KC, American Thoracic Society ERSJRS, Latin American Thoracic S. Diagnosis of Idiopathic Pulmonary Fibrosis. An Official ATS/ERS/JRS/ALAT Clinical Practice Guideline. Am J Respir Crit Care Med 2018: 198(5): e44-e68.

18. Behr J, Gunther A, Bonella F, Dinkel J, Fink L, Geiser T, Geissler K, Glaser S, Handzhhiev S, Jonigk D, Koschel D, Kreuter M, Leuschner G, Markart P, Prasse A, Schonfeld N, 
Schupp JC, Sitter H, Muller-Quernheim J, Costabel U. [German Guideline for Idiopathic Pulmonary Fibrosis]. Pneumologie 2020: 74(5): 263-293.

19. Ryerson CJ, Urbania TH, Richeldi L, Mooney JJ, Lee JS, Jones KD, Elicker BM, Koth LL, King TE, Jr., Wolters PJ, Collard HR. Prevalence and prognosis of unclassifiable interstitial lung disease. Eur Respir J 2013: 42(3): 750-757.

20. Schindelin J, Arganda-Carreras I, Frise E, Kaynig V, Longair M, Pietzsch T, Preibisch S, Rueden C, Saalfeld S, Schmid B, Tinevez JY, White DJ, Hartenstein V, Eliceiri K, Tomancak P, Cardona A. Fiji: an open-source platform for biological-image analysis. Nat Methods 2012: 9(7): 676-682.

21. Tanaka Y, Nakayamada S, Okada Y. Osteoblasts and osteoclasts in bone remodeling and inflammation. Curr Drug Targets Inflamm Allergy 2005: 4(3): 325-328.

22. Xi L, Cao H, Zhu J, Roe OD, Li M, Wu Y, Wang D, Chen Y. OPG/RANK/RANKL axis in stabilization of spontaneously restored sinus rhythm in permanent atrial fibrillation patients after mitral valve surgery. Cardiology 2013: 124(1): 18-24.

23. Tsukasaki M, Asano T, Muro R, Huynh NC-N, Komatsu N, Okamoto K, Nakano K, Okamura T, Nitta T, Takayanagi H. OPG Production Matters Where It Happened. Cell Reports 2020: 32(10).

24. Cawley KM, Bustamante-Gomez NC, Guha AG, MacLeod RS, Xiong J, Gubrij I, Liu Y, Mulkey R, Palmieri M, Thostenson JD, Goellner JJ, O'Brien CA. Local Production of Osteoprotegerin by Osteoblasts Suppresses Bone Resorption. Cell Reports 2020: 32(10).

25. Renshaw SA, Parmar JS, Singleton V, Rowe SJ, Dockrell DH, Dower SK, Bingle CD, Chilvers ER, Whyte MK. Acceleration of human neutrophil apoptosis by TRAIL. J Immunol 2003: 170(2): 1027-1033.

26. Rossi AG, Sawatzky DA, Walker A, Ward C, Sheldrake TA, Riley NA, Caldicott A, Martinez-Losa M, Walker TR, Duffin R, Gray M, Crescenzi E, Martin MC, Brady HJ, Savill JS, Dransfield I, Haslett C. Cyclin-dependent kinase inhibitors enhance the resolution of inflammation by promoting inflammatory cell apoptosis. Nat Med 2006: 12(9): 1056-1064. 
27. Taimr P, Higuchi H, Kocova E, Rippe RA, Friedman S, Gores GJ. Activated stellate cells express the TRAIL receptor-2/death receptor-5 and undergo TRAIL-mediated apoptosis. Hepatology 2003: 37(1): 87-95.

28. Yurovsky VV. Tumor necrosis factor-related apoptosis-inducing ligand enhances collagen production by human lung fibroblasts. Am J Respir Cell Mol Biol 2003: 28(2): 225-231.

29. McGrath EE, Lawrie A, Marriott HM, Mercer P, Cross SS, Arnold N, Singleton V, Thompson AA, Walmsley SR, Renshaw SA, Sabroe I, Chambers RC, Dockrell DH, Whyte MK. Deficiency of tumour necrosis factor-related apoptosis-inducing ligand exacerbates lung injury and fibrosis. Thorax 2012: 67(9): 796-803.

30. Naumnik W, Naumnik B, Niklinska W, Ossolinska M, Chyczewska E. Osteoprotegerin/sRANKL Signaling System in Pulmonary Sarcoidosis: A Bronchoalveolar Lavage Study. Adv Exp Med Biol 2017: 944: 1-7.

31. Van Campenhout A, Golledge J. Osteoprotegerin, vascular calcification and atherosclerosis. Atherosclerosis 2009: 204(2): 321-329.

32. Vij R, Noth I. Peripheral blood biomarkers in idiopathic pulmonary fibrosis. Trans/ Res 2012: 159(4): 218-227.

33. Rosas IO, Richards TJ, Konishi K, Zhang Y, Gibson K, Lokshin AE, Lindell KO, Cisneros J, Macdonald SD, Pardo A, Sciurba F, Dauber J, Selman M, Gochuico BR, Kaminski N. MMP1 and MMP7 as potential peripheral blood biomarkers in idiopathic pulmonary fibrosis. PLoS Med 2008: 5(4): e93.

34. Greene KE, King TE, Jr., Kuroki Y, Bucher-Bartelson B, Hunninghake GW, Newman LS, Nagae H, Mason RJ. Serum surfactant proteins-A and -D as biomarkers in idiopathic pulmonary fibrosis. Eur Respir J 2002: 19(3): 439-446.

35. Kahn N, Rossler AK, Hornemann K, Muley T, Grunig E, Schmidt W, Herth FJF, Kreuter M. C-proSP-B: A Possible Biomarker for Pulmonary Diseases? Respiration 2018: 96(2): 117-126. 
36. Jaffar J, Unger S, Corte TJ, Keller M, Wolters PJ, Richeldi L, Cerri S, Prele CM, Hansbro PM, Argraves WS, Oliver RA, Oliver BG, Black JL, Burgess JK. Fibulin-1 predicts disease progression in patients with idiopathic pulmonary fibrosis. Chest 2014: 146(4): 1055-1063.

37. Boursier J, de Ledinghen V, Zarski JP, Rousselet MC, Sturm N, Foucher J, Leroy V, Fouchard-Hubert I, Bertrais S, Gallois Y, Oberti F, Dib N, Cales P. A new combination of blood test and fibroscan for accurate non-invasive diagnosis of liver fibrosis stages in chronic hepatitis C. Am J Gastroenterol 2011: 106(7): 1255-1263. 


\section{SUPPLEMENTAL DATA}

\section{Osteoprotegerin is elevated in pulmonary fibrosis and associates with IPF \\ progression.}

H. Habibie ${ }^{1,2,3}$, Kurnia S.S. Putri ${ }^{4,5}$, Carian E. Boorsma ${ }^{2}$, David M. Brass ${ }^{6}$, Peter Heukels ${ }^{7}$, Marlies Wijsenbeek ${ }^{7}$, Mirjam Kool ${ }^{7}$, Maarten van den Berge ${ }^{2,8}$, Theo Borghuis ${ }^{9}$, CorryAnke Brandsma ${ }^{2,9}$, C Tji Gan ${ }^{8}$ Peter Olinga ${ }^{4}$, Wim Timens ${ }^{2,9}$, Nicolas Kahn ${ }^{10}$, Michael Kreuter $^{10}$, Janette K. Burgess ${ }^{2,9}$, Barbro N. Melgert ${ }^{1,2}$

${ }^{1}$ University of Groningen, Department of Molecular Pharmacology, Groningen Research Institute for Pharmacy, Groningen, The Netherlands. ${ }^{2}$ University of Groningen, University Medical Centre Groningen, GRIAC Research Institute, Groningen, The Netherlands. ${ }^{3}$ Hasanuddin University, Faculty of Pharmacy, Makassar, Indonesia. ${ }^{4}$ University of Groningen, Department of Pharmaceutical Technology and Biopharmacy, Groningen Research Institute for Pharmacy, Groningen, The Netherlands. ${ }^{5}$ Universitas Indonesia, Faculty of Pharmacy, Depok, Indonesia. ${ }^{6}$ Department of Medicine, Pulmonary Division, Duke University Medical Centre, Durham, NC, USA. ${ }^{7}$ Erasmus MC, Department of Pulmonary Medicine, Rotterdam, The Netherlands. ${ }^{8}$ University of Groningen, University Medical Centre Groningen, Department of Pulmonary Diseases, Groningen, The Netherlands. ' University of Groningen, University Medical Centre Groningen, Department of Pathology and Medical Biology, Groningen, The Netherlands. ${ }^{10}$ Centre for Interstitial and Rare Lung Diseases, Pneumology, Thoraxklinik, University of Heidelberg and German Centre for Lung Research, Heidelberg, Germany

Correspondence should be addressed to:

Prof. Dr. Barbro N. Melgert.

Department of Molecular Pharmacology,

Antonius Deusinglaan 1, 9713 AV Groningen, The Netherlands.

Email: b.n.melgert@rug.nl

Tel: $+31-50-3632947$ 


\section{MATERIALS AND METHODS}

\section{Human tissue}

312 Human fibrotic lung tissue was collected with informed consent from patients with end-stage

313 IPF undergoing lung transplantation at either the University Medical Centre Groningen

314 (UMCG) or at the Erasmus Medical Centre Rotterdam. Human nonfibrotic control lung tissue

315 was obtained at the UMCG from patients undergoing surgical resection for carcinoma or 316 chronic obstructive pulmonary disease (COPD). In cases of tumour resections, histologically 317 normal lung tissue was taken as far distally as possible from the tumour and assessed visually 318 by a pathologist for abnormalities with a standard haematoxylin and eosin staining. Frozen 319 lung tissue was used for the analysis of protein levels of OPG and formalin-fixed paraffin 320 embedded lung tissue was used for the immunohistochemical analyses of OPG and collagen $3211 \alpha 1$.

In Groningen, the study protocol was consistent with the Research Code of the 323 University Medical Centre Groningen,

324 (www.umcg.nl/EN/Research/Researchers/General/ResearchCode/Paginas/default.aspx) and 325 the Dutch national ethical and professional guidelines ("Code of conduct; Dutch federation of 326 biomedical scientific societies"; http://www.federa.org). In Rotterdam, the Medical Ethical 327 Committee approved all protocols followed in that centre.

\section{Isolation of primary human lung fibroblasts}

330 Primary human lung fibroblasts were isolated from lung tissue obtained from 5 nonfibrotic 331 control patients and 7 patients with IPF using a technique described previously [1, 2]. 332 Parenchymal human lung tissue, excluding visible vessels and airways, was cut into 1-2 $\mathrm{mm}^{2}$ 333 pieces that were then cultured for 4-5 weeks in 12-well plates in the presence of complete 334 Ham's F12 medium (BioWhittaker Europe BV, Belgium) supplemented with $10 \%$ fetal calf 335 serum (FCS, Invitrogen, The Netherlands), L-glutamin $2 \mathrm{mM}$, fungizone, penicillin $100 \mathrm{U} / \mathrm{mL}$ 336 and streptomycin $100 \mu \mathrm{g} / \mathrm{mL}$ at $37^{\circ} \mathrm{C}$ in an atmosphere of $5 \% \mathrm{CO}_{2}$. At $25 \%$ confluency, the 337 cells were transferred to T25 flasks. At confluence, cells were trypsinized and cryopreserved 
338 in FCS with $10 \%$ DMSO under slow cooling conditions and eventually stored at $-150^{\circ} \mathrm{C}$. Cells

339 used in the experiments described were maximally passaged seven times.

\section{OPG measurement from primary human lung fibroblasts}

342 Cells were seeded in 96-wells plates (3200 cells/well) for experiments and maintained in 343 Dulbecco's Modified Eagle's Medium (DMEM) Low Glucose (Biowest, Nuaillé, France) 344 supplemented with 10\% Fetal Bovine Serum (FBS), glutaMAX, penicillin $(100 \mathrm{U} / \mathrm{mL})$ and 345 streptomycin $(100 \mu \mathrm{g} / \mathrm{mL})$. Plated cells were grown for $24 \mathrm{~h}$ and transferred to low-serum 346 medium DMEM low glucose supplemented with 0.1\% BSA (Sigma-Aldrich, St. Louis, MO, 347 USA) glutaMAX, penicillin (100 U/mL) and streptomycin $(100 \mu \mathrm{g} / \mathrm{mL})$. After $24 \mathrm{~h}$, supernatants were collected for ELISA analysis of OPG levels and stored at $-20^{\circ} \mathrm{C}$ for later analysis.

\section{Serum from IPF patients and healthy controls}

351 Sera were collected, with informed consent, from 11 IPF patients at their first presentation at 352 the German Centre for Lung Research, University of Heidelberg, Heidelberg, Germany (IRB 353 vote number S-270/2001) and these were compared to sera from 14 matched healthy 354 individuals collected at the UMCG, Groningen, Netherlands (METC numbers 2009/007 and 355 2016/572). IPF diagnosis was assessed according to current guidelines by a multidisciplinary 356 team.

\section{Animal experiments}

359 Male C57BL/6 mice were obtained from Harlan (Zeist, The Netherlands). Animals were 360 maintained with permanent access to food and water in a temperature-controlled environment 361 with a $12 \mathrm{~h}$ dark/light cycle regimen in groups of three with cage enrichment. Treatment with 362 silica did not result in implementing humane end points to prevent further distress and all 12 363 animals were used for analysis. All animal experiments were approved by the Institutional 364 Animal Care and Use Committee. Mice were used in experiments with silica-induced 365 pulmonary fibrosis (DEC6064) and for the preparation of precision cut lung slices 
366 (DEC6416AA). Animal experiments were performed in the animal facility of the University of

367 Groningen according to strict national and international guidelines on animal experimentation.

\section{Silica-induced pulmonary fibrosis in mice}

Male C57BL/6 mice (20-30 gr, age 8-12 weeks, $\mathrm{n}=12$ ) were randomly selected to serve as controls $(n=6)$ or to receive silica to induce fibrosis $(n=6)$ and mice were housed in randomly established groups to avoid cage effects. Sample size was calculated based on pilot experiments. Fibrosis was induced using intratracheal installation of Min-U-Sil 5 crystalline silica (a kind gift from Dr. Andy Ghio, US EPA, Chapel Hill, NC). Mice were anesthetized using isoflurane before they received a single administration of crystalline silica $(0.2 \mathrm{~g} / \mathrm{kg})$ in $50 \mu \mathrm{l}$ $0.9 \%$ saline by intratracheal installation, while control animals received an equivalent volume of $0.9 \%$ saline. Mice were sacrificed after 6 weeks and serum and lung tissue were collected for OPG levels and collagen I content measurements.

\section{Mouse precision-cut lung slices}

381 An ex vivo model of early pulmonary fibrosis development was used to investigate regulation 382 of OPG production by lung tissue. Lungs of 14 healthy male C57BL/6 mice (20-30 gr, age 838312 weeks) were used to make precision-cut lung slices using a method described previously

384 [3]. After sacrifice by exsanguination via the aorta abdominalis under isoflurane anaesthesia, mouse lungs were filled with $1.5 \%$ low-melting temperature agarose in $0.9 \% \mathrm{NaCl}$ (Sigma-

386 Aldrich) and transferred directly into ice-cold University of Wisconsin organ preservation 387 solution (DuPont Critical Care, Waukegab, IL). Lung slices of 5-mm diameter and a weight of 388 about $5 \mathrm{mg}$ (or thickness of 250-300 $\mu \mathrm{m}$ ), were prepared with a Krumdieck tissue slicer 389 (Alabama Research and Development, AL) using ice-cold Krebs-Henseleit Buffer [25 mM D390 glucose (Merck, Darmstadt, Germany), 25 mM NaHCO${ }_{3}$ (Merck), 10 mM HEPES (MP 391 Biomedicals, Aurora, $\mathrm{OH})$, saturated with carbogen $\left(95 \% \mathrm{O}_{2} / 5 \% \mathrm{CO}_{2}\right)$ and adjusted to $\mathrm{pH}$ 7.4]. 392 Lung slices were incubated in 12-well plates in $1.3 \mathrm{~mL}$ DMEM + Glutamax medium [4.5g/L D393 glucose and pyruvate (Gibco) supplemented with a non-essential amino acid mixture (1:100), 
$394100 \mathrm{U} / \mathrm{ml}$ penicillin, $100 \mu \mathrm{g} / \mathrm{ml}$ streptomycin, $45 \mu \mathrm{g} / \mathrm{ml}$ gentamycin and $10 \%$ FCS]. After a $1 \mathrm{~h}$

395 pre-incubation at $37^{\circ} \mathrm{C}$ in a $80 \% \mathrm{O}_{2} / 5 \% \mathrm{CO}_{2}$ atmosphere with continuous shaking at $90 \mathrm{rpm}$,

396 slices were transferred into fresh medium and incubated for $48 \mathrm{~h}$ with or without TGF $\beta(5 \mathrm{ng} / \mathrm{ml})$

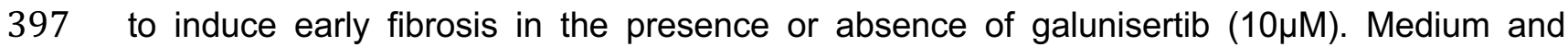

398 treatments were refreshed after 24 hours. Four slices per treatment were pooled for further 399 analyses, while supernatants were collected separately. All samples were stored at $-80^{\circ} \mathrm{C}$ for 400 further analyses.

401

\section{Protein isolation from lung tissue}

403 Protein was isolated from frozen human or mouse lung tissue $(30-40 \mathrm{mg})$ in $0.25 \mathrm{M} \mathrm{Tris} / \mathrm{HCl}$ 404 buffer, 2.5\% Igepal, 0.5\% SDS, Protease Inhibitor Cocktail (Boehringer Mannheim, Germany), $405 \mathrm{pH} 7.5$ by incubating for 1 hour at $4^{\circ} \mathrm{C}$, homogenizing and centrifuging at $16,000 \times \mathrm{g}$ for 30 406 min. Supernatants were collected and the overall protein concentration of the tissue lysates 407 were determined using an RC DC ${ }^{T M}$ Protein Assay based on the Lowry method (cat\#5000111, 408 Bio-Rad, Hercules, CA). Samples were stored at $-80^{\circ} \mathrm{C}$ until further analysis by ELISA analysis.

\section{ELISA}

411 Human and mouse OPG levels in lung tissue, serum and culture supernatants were assessed using ELISA (cat\#DY805 (human), cat\#DY459 (mouse), R\&D Systems (Minneapolis, MN,

413 USA) according to the instructions provided by the manufacturer. One hundred micrograms of 414 tissue lysate total protein in a total of $100 \mu \mathrm{l}$ of sample buffer were analysed. Cell culture media, 415 lung slice culture medium and serum were diluted 1:10, 1:5 and 1:1 respectively before 416 analysis. Total OPG in the lung tissue and lung slices culture medium was corrected for the 417 protein content of the tissue or slices, which was measured by Lowry (BIO-rad RC DC Protein 418 Assay, Bio Rad, Veenendaal, The Netherlands). 


\section{Immunohistochemistry}

421 Immunohistochemical analysis of collagen I and OPG protein in mouse lung tissue was 422 performed on $3 \mu \mathrm{m}$ paraffin-embedded sections of tissue fixed with a zinc-containing buffer 423 [4]. Tissue sections were deparaffinized in xylene, rehydrated in alcohol, rinsed in milliQ water 424 and placed in PBS. Sections were subjected to antigen retrieval $(0.1 \mathrm{~N} \mathrm{Tris-HCl} \mathrm{pH} 9.0$ buffer, overnight at $\left.80^{\circ} \mathrm{C}\right)$. Prior to the incubation with OPG antibody, sections were blocked with $1 \%$ BSA in 5\% nonfat milk (Sigma-Aldrich, St. Louis, MO, USA). Primary antibodies were then incubated for $1 \mathrm{~h}$ at room temperature in the presence of $5 \%$ normal mouse serum. Antibodies used were goat anti-mouse collagen I (1:75, Southern Biotech, Birmingham, AL), rabbit antimouse OPG (1:400, Antibodies-online, Atlanta, GA). Primary antibody incubation was followed by incubation with either a peroxidase-conjugated goat anti-rabbit (1:100, DAKO) or a rabbit anti-goat (1:100, DAKO) secondary antibody, respectively. PO-labeled antibodies were visualized using ImPACT NovaRED kit (Vector, Burlingame, USA) with a haematoxylin counterstain. The amount of collagen deposition in the mouse lung was calculated using ImageScope software (Aperio, Burlingame, USA). After selecting the stained area of the lung sections exluding edges of the tissue, large airway and vessels, a threshold was set to identify positive staining of the tissue (represented by collagen). The percentage of stained-tissue surface per total-tissue surface analysed was then calculated for each section. was performed on formalin-fixed paraffin sections. Human lung sections were deparaffinized and incubated with citrate for antigen retrieval at $100{ }^{\circ} \mathrm{C}$ for 15 minutes. After blocking 441 endogenous peroxidases, slides were incubated overnight with anti-OPG $(1: 300$, Abcam) or 442 Col1a1 (1:500, Abcam) in PBS with $1 \%$ BSA at $4{ }^{\circ} \mathrm{C}$ overnight followed by a goat anti-rabbit 443 peroxidase conjugated secondary antibody (1:100, DAKO) at room temperature for 1 hour. For 444 colour development, NovaRED kit (Vector, Burlingame, USA) was applied to the slides and 445 hematoxylin was used as a nuclear counter stain. Images were captures using a slide scanner 446 (Nanozoomer 2.0 HT, Hamamatsu Photonics) with 20× magnification. Fiji ImageJ was used to 447 quantify the density and distribution of staining [5]. Colour deconvolution vectors in ImageJ 
were optimized to ensure accurate separation of Haematoxylin and NovaRed [6]. The

449 haematoxylin image was used to measure total tissue surface and the NovaRed image was

450 used to calculate the number of positive pixels above the threshold within the image ('area')

451 and the average intensity of the pixels above the threshold ('average intensity'). Macros were 452 used to batch process the images. Data were represented as percentage tissue surface area 453 (NovaRed area/total tissue surface area) and density (average intensity calculated for the 454 whole tissue).

\section{Quantitative Real-time PCR}

457 Total mRNA was isolated from tissues using a Maxwell ${ }^{\circledR}$ LEV simply RNA Cells/Tissue kit (cat\# 458 AS1280, Promega, Madison, $\mathrm{WI}$ ) according to the instructions provided by the manufacturer. 459 Final mRNA concentrations were measured using a Nanodrop ND-100 spectrophotometer 460 (Nanodrop Technologies, Wilmington, DE). All primers were obtained from Sigma-Aldrich 461 (Zwijndrecht, The Netherlands, primers detail can be found in supplemental table 1). 462 Conversion of RNA into cDNA was performed using a reverse transcriptase kit (Promega, 463 Leiden, The Netherlands) in a master-cycler gradient $\left(25^{\circ} \mathrm{C}\right.$ for $10 \mathrm{~min}, 45^{\circ} \mathrm{C}$ for 60 min and $46495{ }^{\circ} \mathrm{C}$ for $5 \mathrm{~min}$ ). Transcript levels of these genes were measured by using $20 \mathrm{ng}$ cDNA per sample in a SensiMix ${ }^{\mathrm{TM}}$ SYBR kit (Bioline, Taunton, MA) and an ABI7900HT sequence

466 detection system (Applied Biosystems, Foster City, CA) with 45 cycles of 10 min $95^{\circ} \mathrm{C}, 15 \mathrm{sec}$ 467 at $95^{\circ} \mathrm{C}$ and $25 \mathrm{sec}$ at $60^{\circ} \mathrm{C}$ followed by a dissociation stage. For each sample, the threshold 468 cycles (Ct values) were calculated using SDS 2.3 software (Applied Biosystems), and mRNA 469 expression was normalized to $18 \mathrm{~s}$

\section{Statistical analyses}

472 Data sets with $\mathrm{n} \leq 8$ were considered non-normally distributed. Statistical differences between 473 two groups were assessed using nonparametric Mann-Whitney $U$ for unpaired data or 474 Wilcoxon for paired data. For data sets with $n \geq 8$, D'agostino-Pearsons test was used to 475 examine normality of the data. If data were normally distributed, a paired or unpaired student's 
476 t-test was used to compare two groups depending on matched data. For the comparison of

477 multiple groups, we used Kruskal Wallis. Correlations were assessed by calculating a 478 nonparametric (Spearman) or parametric (Pearson) correlation coefficient ( $r$ ). Receiver479 operator characteristic (ROC) curves and Kaplan-Meier curves were used to model the utility 480 of serum OPG as a marker of disease progression and to model survival respectively. 
Supplemental table 1. Characteristics of primers used for the quantitative real time PCR

\begin{tabular}{|l|l|l|}
\hline \multicolumn{1}{|c|}{ Gene } & \multicolumn{1}{|c|}{ Forward } & \multicolumn{1}{c|}{ Reverse } \\
\hline collagen 1a1 & 5'-TGACTGGAAGAGCGGAGAGT-'3 & 3'-ATCCATCGGTCATGCTCTCT-'5 \\
\hline fibronectin & 5'-CGGAGAGAGTGCCCCTACTA'3 & 5'-CGATATTGGTGAATCGCAGA-'3 \\
\hline OPG & 5'-ACAGTTTGCCTGGGACCAAA-'3 & 3'-CTGTGGTGAGGTTCGAGTGG-'5 \\
\hline PAI1 & 5'-GCCAGATTTATCATCAATGACTGGG-'3 & 3'-GGAGAGGTGCACATCTTTCTCAAAG-55 \\
\hline $18 \mathrm{~s}$ & 5'-CTTAGAGGGACAAGTGGCG-'3 & 3'- ACGCTGAGCCAGTCAGTGTA-'5 \\
\hline
\end{tabular}

Supplemental table 2. Selected threshold values from the ROC curve (area under curve,

$0.85 ; 95 \% \mathrm{Cl}, 0.62-1.09 ; \mathrm{p}=0.058 ; n=11)$. Values in bold were used for further analysis

\begin{tabular}{|c|c|c|}
\hline $\begin{array}{c}\text { Threshold value } \\
\text { (pg/ml) }\end{array}$ & Sensitivity\% & Specificity\% \\
\hline$>735.9$ & 100,0 & 14,29 \\
\hline$>954.1$ & 100,0 & 28,57 \\
\hline$>1035$ & 100,0 & 42,86 \\
\hline$>1080$ & 100,0 & 57,14 \\
\hline$>1234$ & 100,0 & 71,43 \\
\hline$>1423$ & 75,00 & 71,43 \\
\hline$>1558$ & 50,00 & 71,43 \\
\hline$>1896$ & 50,00 & 85,71 \\
\hline$>2560$ & 50,00 & 100,0 \\
\hline$>3225$ & 25,00 & 100,0 \\
\hline
\end{tabular}


a)

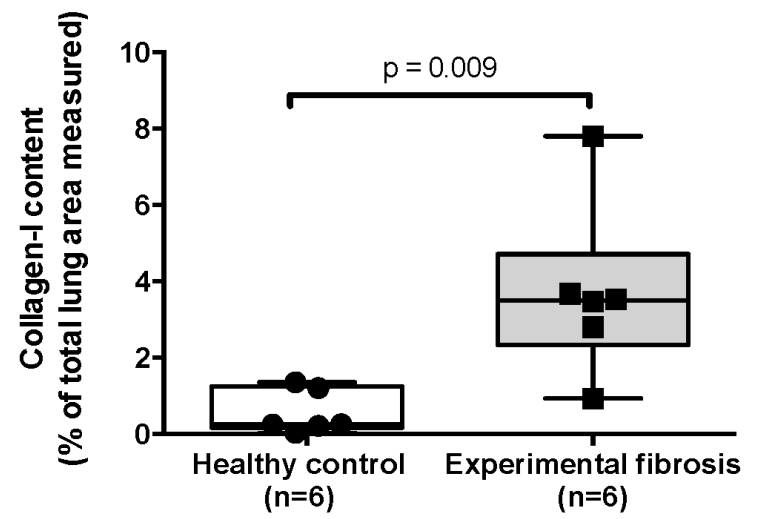

b)

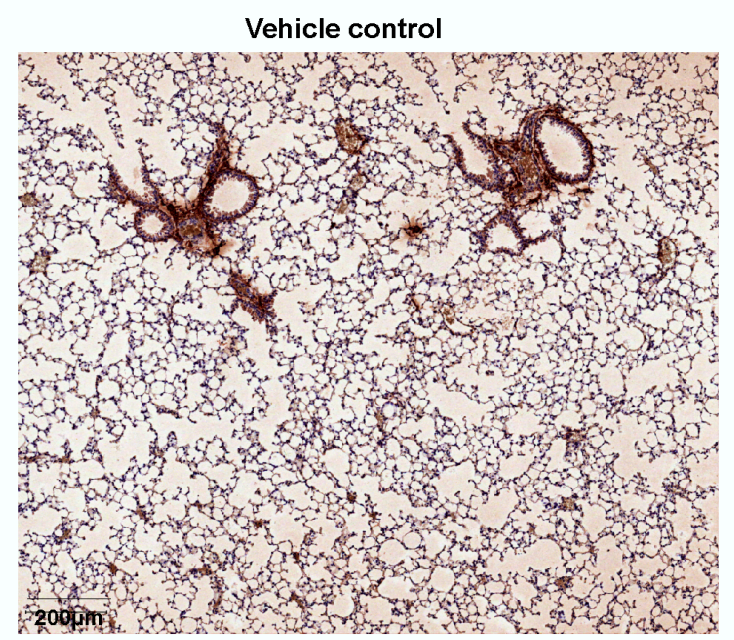

c)
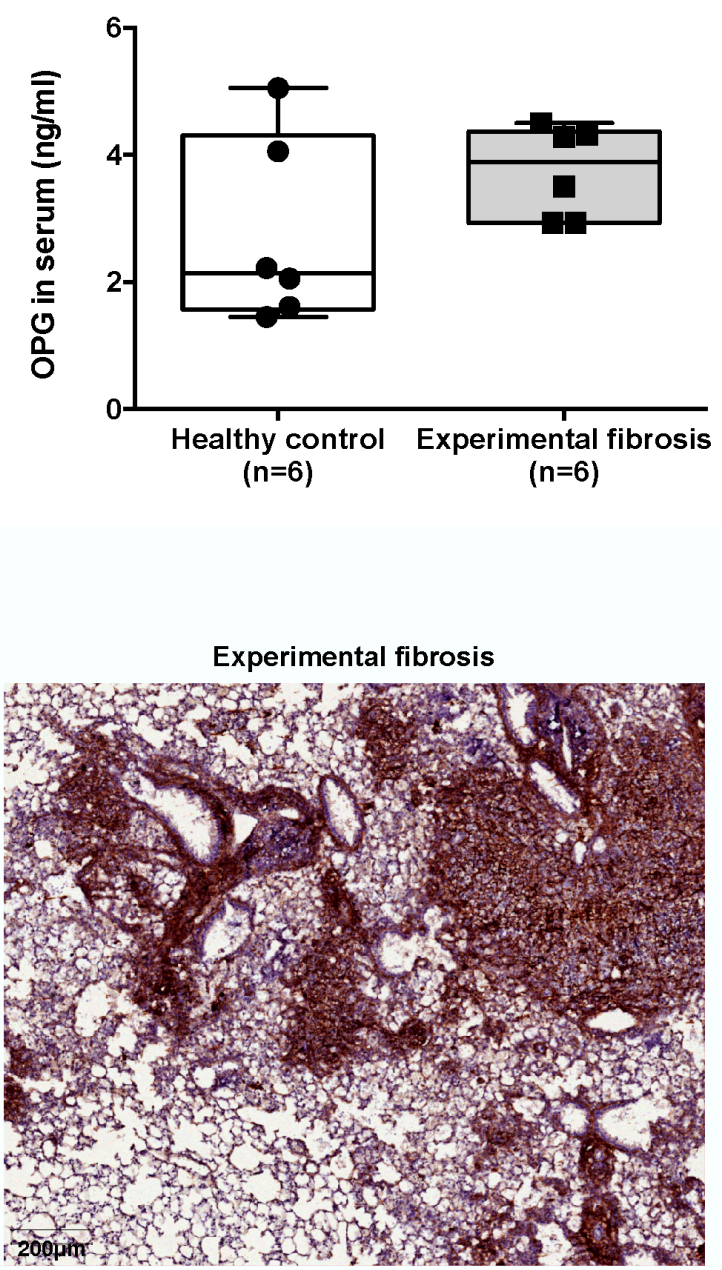

Supplemental data figure 1. Collagen I is abundantly present in the lung tissue of mice with silica-

488 induced fibrosis. C57BL/6 mice were treated intratracheally with saline or Min-U-Sil 5 crystalline silica and sacrificed after 6 weeks. (a) Collagen I protein content was higher in lungs of mice exposed to silica (fibrosis, $n=6$ ) as compared to healthy controls $(n=6)$.

(b) Representative pictures of collagen I deposition, showing that collagen I deposition was higher in the lungs of mice exposed to silica as compared to saline-exposed controls. Collagen I expression is indicated by the red color. (c) OPG levels in serum were not significantly different between control $(n=6)$ and silica-exposed mice $(n=6)$.

494 Differences between groups were tested with a Mann Whitney $U$ test. $p<0.05$ was considered statistically significant. 
a)

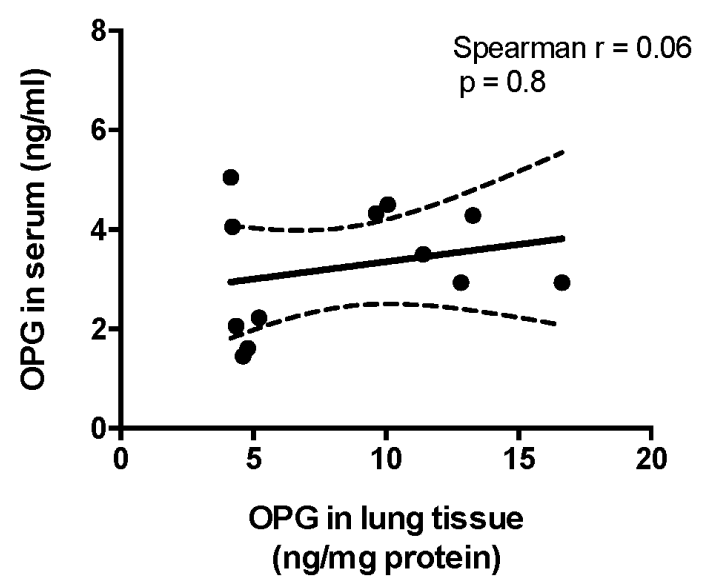

b)

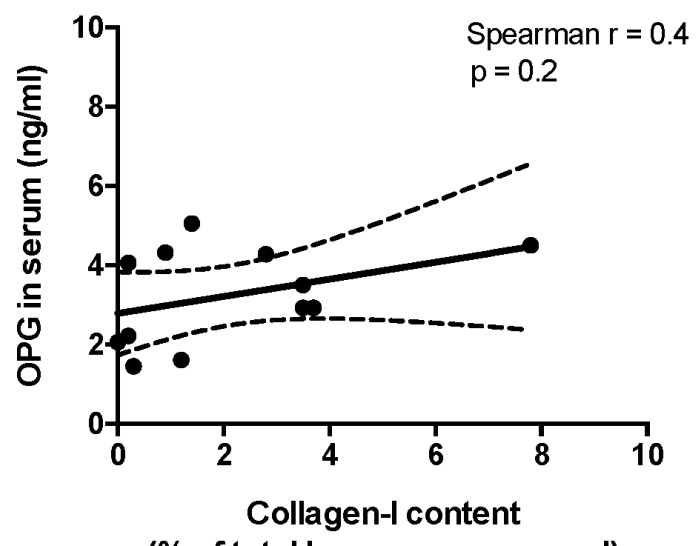

( $\%$ of total lung area measured)

Supplemental data figure 2. OPG levels in serum do not correlate with OPG levels or collagen I content in lung tissue of control mice and mice with silica-induced fibrosis. C57BL/6 mice were treated intratracheally with saline $(n=6)$ or Min-U-Sil 5 crystalline silica $(n=6)$ and sacrificed after 6 weeks. OPG levels in serum/tissue and collagen I content were determined using ELISA and immunohistochemistry respectively. (a) OPG serum levels do not correlate with OPG levels in mouse lung tissue. (b) OPG serum levels do not correlate with collagen content in mouse lung tissue.

504 Correlation was calculated using a Spearman test and $p<0.05$ was considered significant.

a)

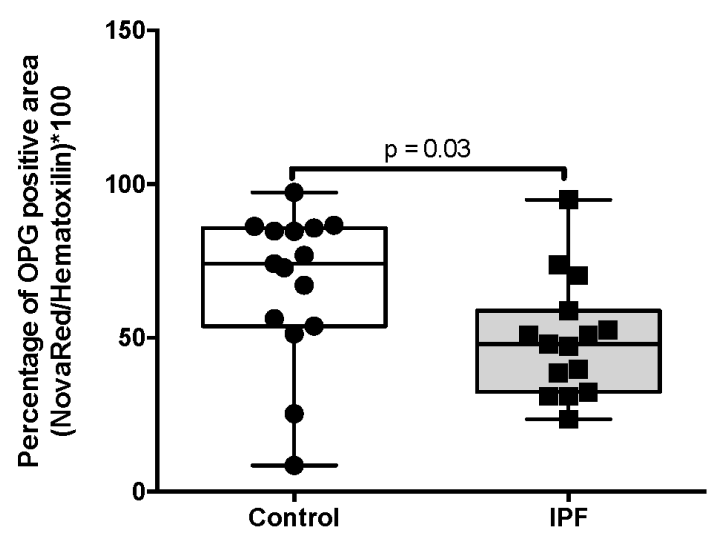

b)

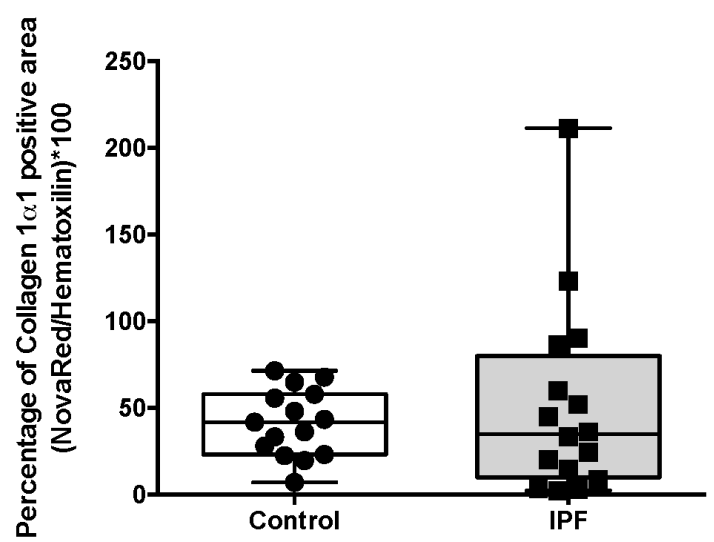

Supplemental data figure 3. Percentage of OPG and collagen 1a1 positive area in the lung of patients with and without IPF. Lung section of control patients and patients with IPF were stained for OPG and collagen 1a1. Percentage of OPG- (a) and collagen 1a1- positive area (b) in human control and IPF lung tissue was lower in IPF compared to control lung tissue. Differences between groups were 
511 tested with unpaired student $t$ test (a) or a Mann Whitney $U$ test (b). $p<0.05$ was considered statistically 512 significant.

513

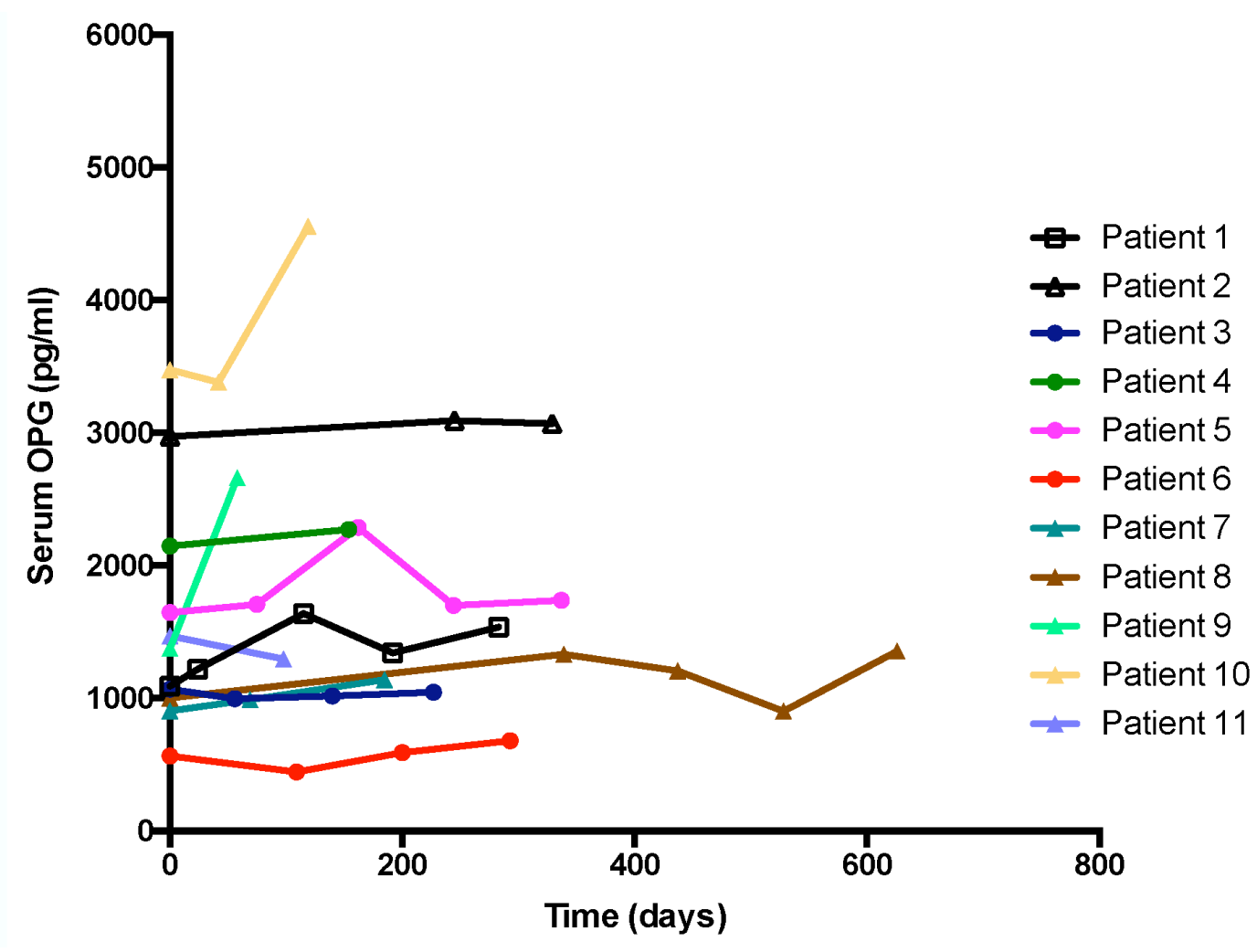

515 Supplemental data figure 4. OPG levels did not change over time within patients with IPF.

516 Serum of patients with IPF was collected at multiple time points and OPG levels were measured by 517 ELISA. 


\section{References}

1. Noordhoek JA, Postma DS, Chong LL, Menkema L, Kauffman HF, Timens W, van Straaten JF, van der Geld YM. Different modulation of decorin production by lung fibroblasts from patients with mild and severe emphysema. COPD 2005: 2(1): 17-25.

2. Noordhoek JA, Postma DS, Chong LL, Vos JT, Kauffman HF, Timens W, van Straaten JF. Different proliferative capacity of lung fibroblasts obtained from control subjects and patients with emphysema. Exp Lung Res 2003: 29(5): 291-302.

3. Olinga P, Merema MT, de Jager MH, Derks F, Melgert BN, Moshage H, Slooff MJ, Meijer DK, Poelstra K, Groothuis GM. Rat liver slices as a tool to study LPS-induced inflammatory response in the liver. $J$ Hepatol 2001: 35(2): 187-194.

4. Beckstead JH. A simple technique for preservation of fixation-sensitive antigens in paraffin-embedded tissues. J Histochem Cytochem 1994: 42(8): 1127-1134.

5. Schindelin J, Arganda-Carreras I, Frise E, Kaynig V, Longair M, Pietzsch T, Preibisch S, Rueden C, Saalfeld S, Schmid B, Tinevez JY, White DJ, Hartenstein V, Eliceiri K, Tomancak P, Cardona A. Fiji: an open-source platform for biological-image analysis. Nat Methods 2012: 9(7): 676-682.

6. Ruifrok AC, Johnston DA. Quantification of histochemical staining by color deconvolution. Anal Quant Cytol Histol 2001: 23(4): 291-299. 